\title{
Sustainable hydrogenation of Aliphatic Acyclic Primary Amides to \\ Primary Amines with Recyclable Heterogeneous Ruthenium- Tungsten Catalysts
}

\author{
Robin Coeck, Sarah Berden and Dirk E. De Vos, cMACS, KU Leuven, Leuven,
}

\section{Belgium}

\begin{abstract}
The hydrogenation of amides is a straightforward method to produce (possibly bio-based) amines. However current amide hydrogenation catalysts have only been validated in a rather limited range of toxic solvents and the hydrogenation of aliphatic (acyclic) primary amides has been seldomly investigated. Here, we report the use of a new and relatively cheap ruthenium-tungsten bimetallic catalyst in the green and benign solvent cyclopentyl methyl ether (CPME). Besides the effect of the Lewis acid promotor, $\mathrm{NH}_{3}$ partial pressure is identified as the key parameter leading to high primary amine yields. In our model reaction with hexanamide, yields of up to $83 \%$ hexylamine could be achieved. Beside the $\mathrm{NH}_{3}$ partial pressure, we investigated the effect of the catalyst support, $P G M$-Lewis acid ratio, $\mathrm{H}_{2}$ pressure, temperature, solvent tolerance and product stability. Finally, the catalyst was characterized and proven to be very stable and highly suitable for the hydrogenation of a broad range of amides.
\end{abstract}

\section{Introduction}

Catalytic hydrogenation of amides is a green and sustainable method for the production of valuable amines. With an annual aliphatic amine consumption of more than 2 Mton, amines are widely used for the synthesis of e.g. pharmaceuticals, agrochemicals, dyes, polymers, fabric softeners etc. ${ }^{1-2}$ However, the hydrogenation of amides is a challenging reaction, because of their high stability. ${ }^{3}$

Traditionally, amide reduction is achieved with either copper chromite-based hydrogenation catalysts or by applying an excess of hydride reagents. Both methods have severe shortcomings and lack sustainability. The requirement of stoichiometric amounts of hydride reagents such as $\mathrm{LiAlH}_{4}$ or $\mathrm{NaBH}_{4}$ results in large quantities of inorganic chemical waste and an extensive product workup, whereas copper chromite-based catalysts require extreme reaction conditions (e.g. $>200$ bar $\mathrm{H}_{2}, 250-350^{\circ} \mathrm{C}$ ) and high catalyst loadings, require specific disposal and generally have a low selectivity for the primary amine..$^{4-6}$

Over the last few decades, progress has been made with the development of heterogeneous bimetallic catalysts operating under mild reaction conditions. The first such catalyst was reported in 1988 in a BP patent, which claimed a $\mathrm{Pd} / \mathrm{Re} /$ high surface area graphite/zeolite $4 \mathrm{~A}$ catalyst for the reduction of amides at 130 bar $\mathrm{H}_{2}$ and $200^{\circ} \mathrm{C}$. Currently, a variety of bimetallic catalysts have been reported, containing a platinum group metal ( $\mathrm{Pt}, \mathrm{Pd}, \mathrm{Rh}$ or $\mathrm{Ru}$ ) promoted by a group 5,6 or 7 metal oxide ( $\mathrm{V}$, Mo or $\mathrm{Re}$ ); these catalysts are active within a operational window of $70-200^{\circ} \mathrm{C}$ and $30-100$ bar $\mathrm{H}_{2 \cdot}{ }^{3,7-23,43}$ Although several amides have successfully been hydrogenated to the corresponding amines with high yields and/or selectivity (at least $70 \%$ yield), several issues still need to be addressed. First, these catalysts have only been validated in a surprisingly narrow range of toxic solvents e.g. 1,2-dimethoxyethane (DME), hexane and 1,4-dioxane. A smart solvent choice however, can drastically reduce pollution, contribute to a better air quality and reduce the overall environmental footprint of the 
process. ${ }^{24}$ Secondly, the hydrogenation of aliphatic, acyclic primary amides has been rarely investigated with these new bimetallic catalysts; most reports use cyclic or more activated amides as reactants, such as $\varepsilon$-caprolactam or $\mathrm{N}$-acetylmorpholine. In as far as aliphatic acyclic primary amides are considered, they are usually converted to the alcohol or secondary amine, or must be hydrogenated under extreme reaction conditions (e.g. in liquid ammonia, at high temperatures etc.) to "selectively" obtain the primary amine. ${ }^{6}$ Nevertheless, a mild catalytic system able to selectively reduce aliphatic acyclic primary amides, could be a powerful tool to produce even bio-based primary amines. As of today, several bio-based amines, e.g. 1,10-diaminodecane and fatty amines, are synthesized from the corresponding carboxylic acids in a multistep process: first, the carboxylic acid reacts with ammonia at high temperature; next, the resulting amide is dehydrated over an alumina or zinc oxide catalyst at $280-400^{\circ} \mathrm{C}$, and finally, the nitrile is hydrogenated to the amine at a temperature of $80-140^{\circ} \mathrm{C}$ with 10-40 bar $\mathrm{H}_{2}$, over a nickel catalyst.,25-29 This energy-intensive dehydration-hydrogenation process could be significantly shortened by a direct aliphatic amide reduction, requiring less energy. Additionally, we expect that in the near future this pathway will receive an increase in interest, since more and more amines may be produced from bio-based platform molecules, e.g. butyric acid, propionic acid, adipic acid etc. ${ }^{30-31}$ In this work, we report on $\mathrm{RuWO}_{\times} / \mathrm{MgAl}_{2} \mathrm{O}_{4}$ as a new and recyclable catalyst for the selective hydrogenation of aliphatic primary amides in cyclopentyl methyl ether (CPME) and under mild hydrogenation conditions, i.e. with limited addition of $\mathrm{NH}_{3}$ and $\mathrm{H}_{2}$. To our knowledge, this is the first report of an amide hydrogenation process in CPME as a benign and environmentally friendly reaction solvent. ${ }^{32-33}$

\section{Experimental}

Supported bimetallic M-M'O $\mathrm{X}_{\mathrm{x}}$ catalysts (where $\mathrm{M}=\mathrm{Ru}$, Rh or $\mathrm{Pt}, \mathrm{M}^{\prime}=\mathrm{V}$, Mo or $\mathrm{W}$ and support $=\mathrm{SiO}_{2}, \mathrm{TiO}_{2}$ or $\mathrm{MgAl}_{2} \mathrm{O}_{4}$ spinel) were prepared with $4 \mathrm{wt} \% \mathrm{M}$ and a $\mathrm{M}-\mathrm{M}$ ' ratio of 1-8 by impregnation. First, in a typical synthesis of $\mathrm{RuWO} \times \mathrm{MgAl}_{2} \mathrm{O}_{4}, \mathrm{RuCl}_{3} \cdot \mathrm{xH}_{2} \mathrm{O}$ (0.52 mmol), $\left(\mathrm{NH}_{4}\right)_{10} \mathrm{H}_{2}\left(\mathrm{~W}_{2} \mathrm{O}_{7}\right)_{6}\left(0.065 \mathrm{mmol}\right.$ of tungsten), $\mathrm{MgAl}_{2} \mathrm{O}_{4}(1.25 \mathrm{~g})$ and water $(12 \mathrm{~mL})$ are mixed together and stirred at ambient temperature to evaporate water. Secondly, when all the water is removed, the pre-catalyst is dried further overnight in an oven at $60^{\circ} \mathrm{C}$. Finally, the material is granulated $(250-500 \mu \mathrm{m})$ and reduced at $450^{\circ} \mathrm{C}\left(4^{\circ} \mathrm{C} \mathrm{min}-1,100 \mathrm{~mL} \mathrm{~min}^{-1} \mathrm{H}_{2}\right.$, for $\left.4 \mathrm{~h}\right)$ in a quartz U-tube. Catalysts with $\mathrm{Rh}$ or $\mathrm{Pt}$ are first oxidized at $350^{\circ} \mathrm{C}$ and reduced afterwards. Initially $\mathrm{RuWO} \mathrm{x}_{\times} / \mathrm{SiO}_{2}-\mathrm{Ca}^{2+}$ catalysts were prepared by first stirring $\mathrm{RuWO} \times \mathrm{SiO}_{2}(0.1 \mathrm{~g})$ in a solution of $\mathrm{Ca}(\mathrm{OH})_{2}$ in water $(0.005 \mathrm{M}, 10 \mathrm{~mL})$ overnight. Next the catalyst was filtered and dried in an oven at $150^{\circ} \mathrm{C}$ for $4 \mathrm{~h}$. However, this lowered the catalytic activity due to tungstate leaching. This method was improved by depositing $0.025 \mathrm{mmol}$ of $\mathrm{Ca}^{2+}$ (or $0.05 \mathrm{mmol} \mathrm{Na}$, 
$\mathrm{K}^{+}$or $\mathrm{Cs}^{+}$) on $1 \mathrm{~g}$ of $\mathrm{RuWO}_{x} / \mathrm{SiO}_{2}$ via incipient wetness impregnation and drying the material at $150^{\circ} \mathrm{C}$ for $4 \mathrm{~h} . \mathrm{PtVO}_{\mathrm{x}} / \mathrm{HAP}$ was synthesized as described by Mitsudome (2017).

With the prepared catalysts, reactions were performed in a $25 \mathrm{~mL}$ high pressure Parr batch reactor. In a typical reaction, the reactor is filled with an amide (e.g. hexanamide), RuWO $\times \mathrm{MgAl}_{2} \mathrm{O}_{4}$ (4 wt\% Ru, Ru-W = 1-8, $5 \mathrm{~mol} \% \mathrm{Ru}$ ), undecane (internal standard, $20 \mu \mathrm{L}$ ) and cyclopentyl methyl ether (CPME, $10 \mathrm{~mL}$ ). Then, the reactor is sealed, purged $\left(3 \times \mathrm{N}_{2} ; 3 x\right.$ $\mathrm{H}_{2}$ ) and successively pressurized with the desired amounts of $\mathrm{NH}_{3}$ and $\mathrm{H}_{2}$ (typically 6 bar $\mathrm{NH}_{3}$ and 50 bar $\left.\mathrm{H}_{2}\right)$. After an appropriate reaction time at the desired temperature $\left(200^{\circ} \mathrm{C}\right.$, stirred at $830 \mathrm{rpm}$ ), the reactor is cooled down in an ice bath. The pressure is then released after which the reactor can be opened. The reaction mixture is transferred to a glass reaction vial $(11 \mathrm{~mL})$ which is then sealed and centrifuged. The mixture is then analyzed via GC, GC-MS and NMR.

\section{Results and discussion}

At the onset of our research, several Ru-based catalysts were modified with different molar ratios of cheap group 5 to 7 metal oxides (Mo, W and V). The solids were screened in the hydrogenation of hexanamide (1) to hexylamine (3), allowing to determine the best metal combination and composition for the reduction of aliphatic acyclic primary amides. These initial experiments were performed at $180^{\circ} \mathrm{C}$ with 40 bar $\mathrm{H}_{2}, 0.5 \mathrm{~mol} \% \mathrm{Ru}$ in DME for $16 \mathrm{~h}$ (Figure 1). For all metal oxides, there appears to be a clear optimum at a Ru/Metal oxide ratio of 8 . $R u W O_{x} / \mathrm{SiO}_{2}(\mathrm{Ru} / \mathrm{W}=8)$ was proven to be the best catalyst, yielding $38 \%$ hexylamine (3) at $69 \%$ conversion; alternative compositions are $\mathrm{RuMoO} \times \mathrm{SiO}_{2}$ and $\mathrm{RuVO} \times \mathrm{SiO}_{2}$ respectively, with a yield of $35 \%$ and $30 \%$ hexylamine (3) at $67 \%$ and $70 \%$ conversion. All these catalysts are superior when compared to simple Ru-catalysts, such as $\mathrm{Ru} / \mathrm{SiO}_{2}$. Beside the formation of our desired product, hexanol (2) and dihexylamine (4) were formed as well. Especially secondary amine formation is a predominant side reaction. Interestingly, unsupported Ru-Mo nanoparticles, as already described by Beamson et al., allowed to obtain $77 \%$ butylamine yield (and $22 \%$ butanol) at $160^{\circ} \mathrm{C}$, with 100 bar $\mathrm{H}_{2}$, in DME. Moreover, further addition of any metal oxide to a catalyst with the same ratio of 8-1, lowered the catalytic activity. This drop in activity is presumably caused by a coverage of the $\mathrm{Ru}$ particles, lowering the availability of $\mathrm{H}^{*}$ species for the reduction of hexanamide. We also noticed that the Lewis acid metal oxides must be located on (or in contact with) the $\mathrm{Ru}$ particles, since catalysts prepared by consecutive deposition of first $\mathrm{W}$, followed by $\mathrm{Ru}$, did not show a superior catalytic activity. In our further experiments, we choose to work with $\mathrm{RuWO} / \mathrm{SiO}_{2}$, since this catalyst performed best. 


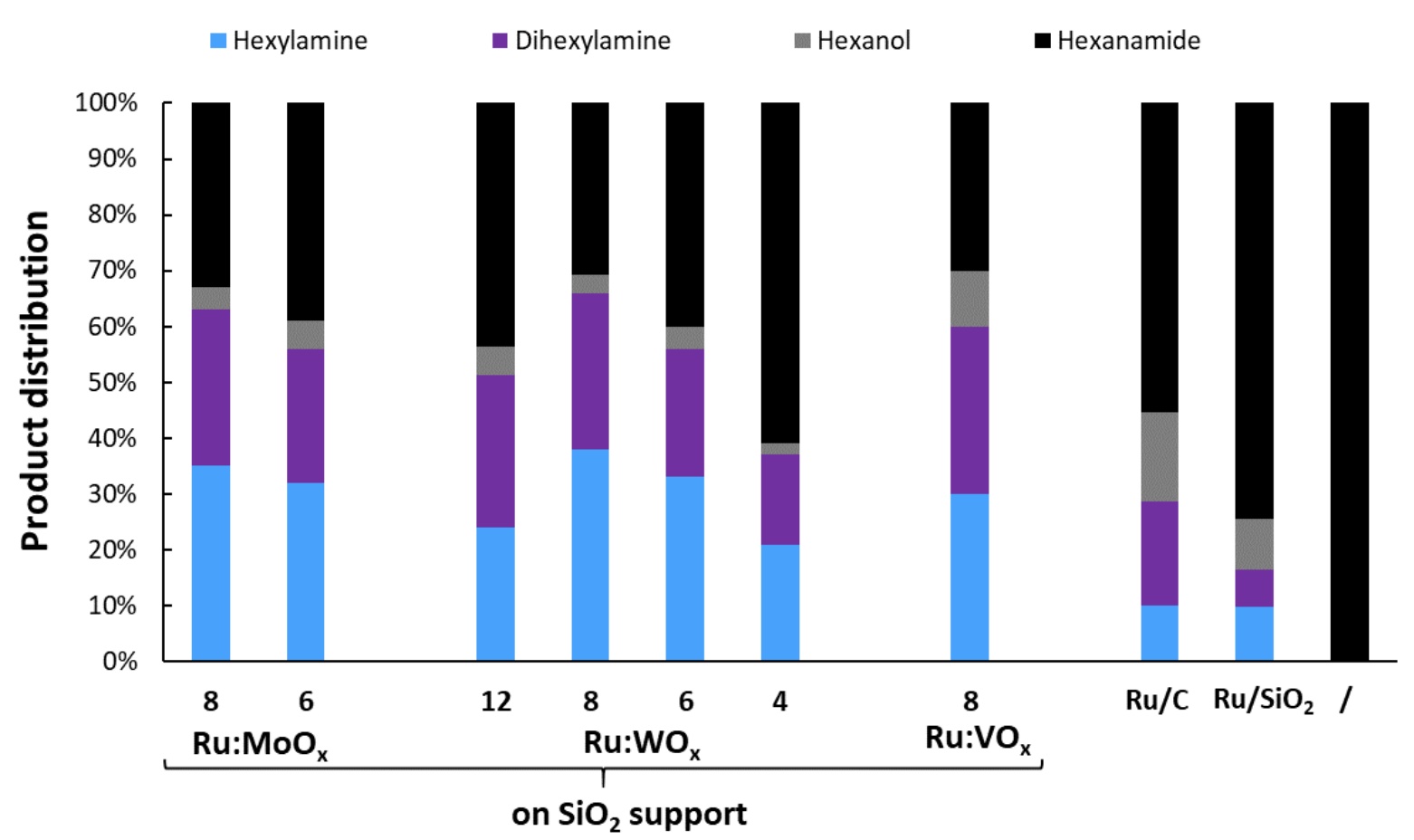

Figure 1 - Variation of the catalysts' metal combination and composition. Reaction conditions: hexanamide $(1 \mathrm{mmol}), 180^{\circ} \mathrm{C}$, 40 bar $\mathrm{H}_{2} ; 0.5 \mathrm{~mol} \% \mathrm{Ru}(4 \mathrm{wt} \% \mathrm{Ru}$ on catalyst, $5 \mathrm{wt} \% \mathrm{Ru}$ for $\mathrm{Ru} / \mathrm{C})$, undecane $(20 \mu \mathrm{L})$, DME $(10 \mathrm{~mL}), 16 \mathrm{~h}$.

Next, the solvent tolerance of the RuWO $\mathrm{x}_{\mathrm{x}}$-catalyst was investigated. As mentioned, the commonly used DME is a very toxic compound. Furthermore, it easily forms explosive peroxides which generally makes it unsafe to work with, especially in contact with $\mathrm{H}_{2} \cdot{ }^{34} \mathrm{~A}$ benign, preferably bio-based reaction solvent would be far more desirable. Therefore, the hydrogenation activity of $\mathrm{RuWO}_{\times} / \mathrm{SiO}_{2}$ was tested in several solvents, selected from green solvent guides (Figure 2). ${ }^{35}$ The reduction of hexanamide (1) could be successfully achieved in any ether solvent, but not in an alcohol. We suggest that the amide-catalyst bond is too weak to sufficiently overcome the catalyst's interaction with the hydroxyl group of an alcohol solvent. Ethers interact a lot less with bimetallic catalysts and are therefore excellent solvents for amide hydrogenation. It can be noticed that the hydrogenation rate increases with decreasing solvent polarity ( dielectic constant, $\left.\varepsilon_{r}\right)$ : DME $\left(\varepsilon_{r}=7.2\right)<\operatorname{MeTHF}\left(\varepsilon_{r}=7\right)<\operatorname{CPME}$ $\left(\varepsilon_{r}=4.76\right)<\operatorname{TAME}\left(\varepsilon_{r}=2.6\right)$. However, the rate of secondary amine formation also increases in the same order (Supporting information, Figure $S$ 2). CPME was selected as the best reaction solvent for a number of reasons; first, there appears to be a good balance between hydrogenation activity and secondary amine formation. Secondly, the low heat of vaporization (CPME: $289.5 \mathrm{~kJ} / \mathrm{kg}$ vs MeTHF: $364.4 \mathrm{~kJ} / \mathrm{kg}$ ) and extremely low solubility of water in CPME (0.3 g water/100 g CPME) ensure an easy and energy-saving workup when applied in a real industrial process. Thirdly, CPME is very stable and resistant to peroxide formation, which makes it safe to work with. ${ }^{36}$ After a typical reaction in CPME, a concentration of less than $0.001 \mathrm{M}$ cyclopentane was observed. These traces of cyclopentane do not interfere with the reaction, thus the solvent can be reused for many 
cycles. The other cleavage product, methanol, was not detected. Possibly, methanol is transformed to volatile consecutive products e.g. $\mathrm{CH}_{4}$ or to methylamine, which migrate to the gas phase. ${ }^{43}$

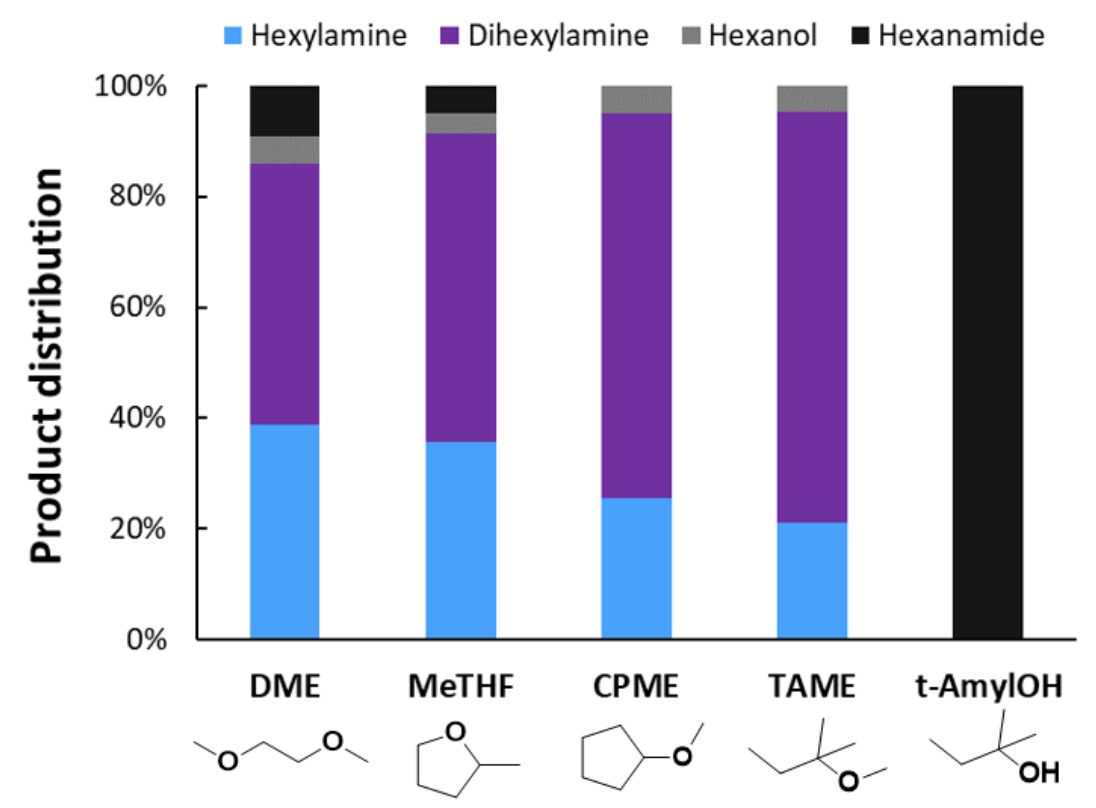

Figure 2 - Variation of the reaction solvent for the hydrogenation of hexanamide. Reaction conditions: hexanamide $(1 \mathrm{mmol})$, $180^{\circ} \mathrm{C}, 40$ bar $\mathrm{H}_{2}, 1 \mathrm{~mol} \% \mathrm{Ru}\left(\mathrm{RuWO}_{x} / \mathrm{SiO}_{2}\right)$, undecane $(20 \mu \mathrm{L})$, solvent $(10 \mathrm{~mL}), 16 \mathrm{~h}$.

After selecting CPME as a reaction solvent, a broader catalyst screening was performed (Figure 3 \& Figure S 3, Table S 1). Commercial PGM on carbon supports performed very poorly, except for Ru/C. Such "single metal catalysts" can be further improved by depositing small amounts of tungsten on the surface; not only does this improve the catalytic activity, also the selectivity for $\mathrm{C}-\mathrm{O}$ cleavage (amine formation) over $\mathrm{C}-\mathrm{N}$ cleavage (alcohol formation) increases (Figure $3 \&$ Figure $S 5$ ). However, the formation of secondary amines cannot be suppressed by tungsten deposition. Nonetheless, since amine condensation requires a combination of metal and acid catalysis, one may improve the selectivity for the primary amine by lowering the amount of Brønsted acid sites. This could either be achieved by wielding more basic (or at least less acidic) supports, e.g. rutile, or by stirring the slightly acidic RuWO on fumed silica in a basic solution of e.g. $\mathrm{Ca}(\mathrm{OH})_{2}$, followed by a drying step (Figure S 4). ${ }^{37-38}$ Regarding this second option, despite the catalyst's high stability, one must be careful not to leach out any tungsten as tungstate, since this will lower the catalytic activity. In this catalyst screening, $\mathrm{RuWO} \times{ }_{x} / \mathrm{SiO}_{2}-\mathrm{Ca}^{2+}$ was the catalyst with the highest selectivity for the primary amine (63\% selectivity, $53 \%$ conversion); the reaction proceeds without hydrolysis of hexanamide (1) (Figure 3 and Figure $S 3$ ). More remarkably, our RuWO ${ }_{x} / \mathrm{SiO}_{2}-\mathrm{Ca}^{2+}$ performs better than $\mathrm{PtVO}_{x} / \mathrm{Hydroxyapatite}$ (Figure 3), described by Mitsudome et al. in 2017, an extremely active catalyst able to reduce a variety of amides at reaction conditions as low as $70^{\circ} \mathrm{C}$ and 1 bar $\mathrm{H}_{2}{ }^{7}$ 


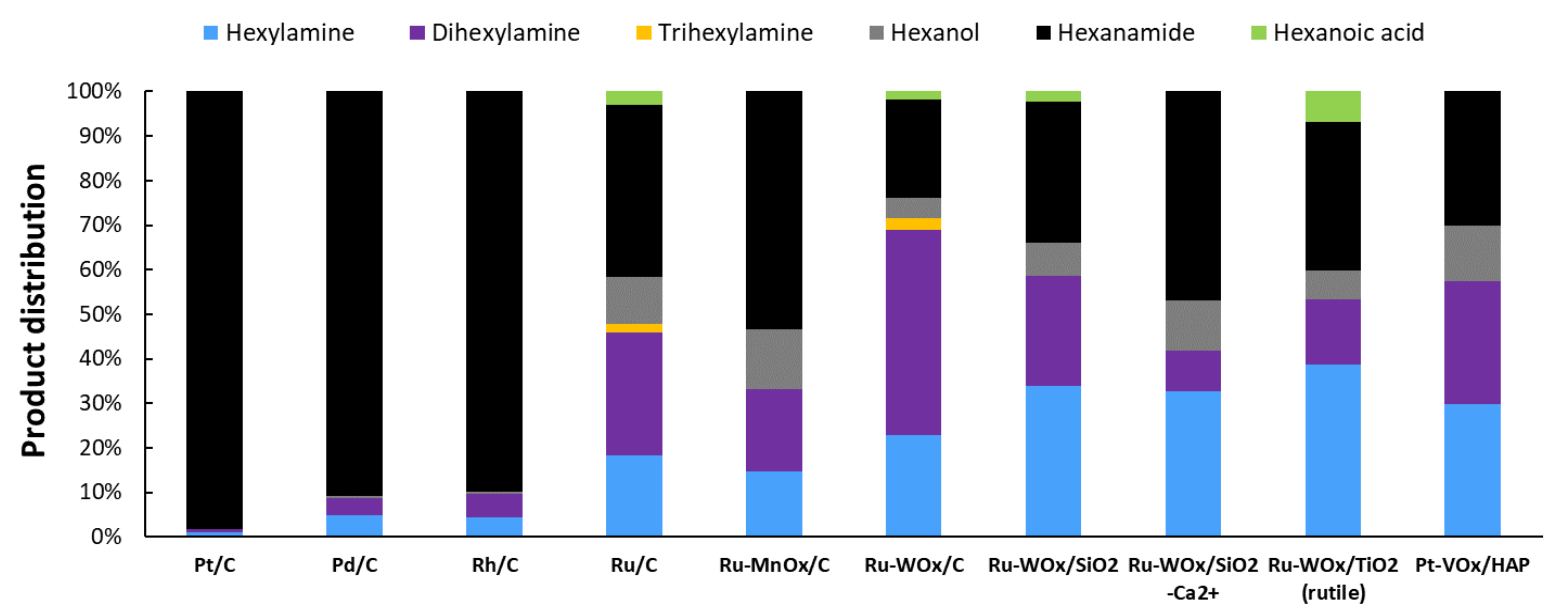

Figure 3 - Variation of the amide hydrogenation catalyst. Reaction conditions: hexanamide $(1 \mathrm{mmol}), 180^{\circ} \mathrm{C}, 50$ bar $\mathrm{H}_{2} ; 0.5$ bar $\mathrm{NH}_{3} ; 0.5 \mathrm{~mol} \% \mathrm{Ru}$ (or same weight other PGM), undecane (20 $\left.\mu \mathrm{L}\right)$, CPME (10 mL), $16 \mathrm{~h}$.

To further investigate the amide hydrogenation and unravel the mechanisms behind it, hydrogenation experiments with $\mathrm{RuWO}_{\times} / \mathrm{SiO}_{2}-\mathrm{Ca}^{2+}$ were performed at different temperatures $\left(160^{\circ} \mathrm{C}, 180^{\circ} \mathrm{C}\right.$ and $200^{\circ} \mathrm{C}$ ) and time profiles were recorded (Figure 4). All three time profiles have a similar shape. In two parallel pathways, hexanamide (1) is hydrogenated towards hexylamine (3) (C-O cleavage) and hexanol (2) (C-N cleavage). From the initial slopes, it is deduced that amine formation is promoted over alcohol formation when increasing the temperature. After this initial phase, a consecutive product is detected, viz. dihexylamine (4). Although it can be formed from solely the primary amine, dihexylamine (4) is mainly the result of a condensation reaction between hexanol (2) and hexylamine (3) since this reaction is much faster (Figure $S 4$ ). To be more precise, both the amine and alcohol are at constant equilibrium with trace amounts of their corresponding imine and aldehyde. These unsaturated molecules will react with amines, and after $\mathrm{NH}_{3}$ elimination and reduction, secondary or even tertiary amines are formed (as for $\mathrm{Ru} / \mathrm{C}$ ). Hexanol (2) can be transformed into hexylamine (3) as well (after reaction with $\mathrm{NH}_{3}$ ); at $160^{\circ} \mathrm{C}$ the rates of $\mathrm{C}-\mathrm{O}$ and $\mathrm{C}-\mathrm{N}$ cleavage are roughly the same. Nevertheless, after a reaction time of $5 \mathrm{~h}$, the hexanol (2) yield reaches a maximum while the amount of hexylamine (3) still increases. These observations gave rise to the reaction network depicted in Figure 5. For all the screened reaction temperatures, a maximum in hexylamine (3) yield was observed at $90-92 \%$ conversion, with 50 bar $\mathrm{H}_{2}, 0.5$ bar $\mathrm{NH}_{3}$, in CPME. The hydrogenation experiment at $200^{\circ} \mathrm{C}$ resulted in the highest yield of $50 \%$ hexylamine (3) (90\% conversion). We did not perform hydrogenation experiments above $200^{\circ} \mathrm{C}$, regarding the higher energy costs and increased rate of undesired side reactions, e.g. amine-imine condensation and deamination (at $200^{\circ} \mathrm{C}$, $<1 \%$ hexane yield at full conversion). 

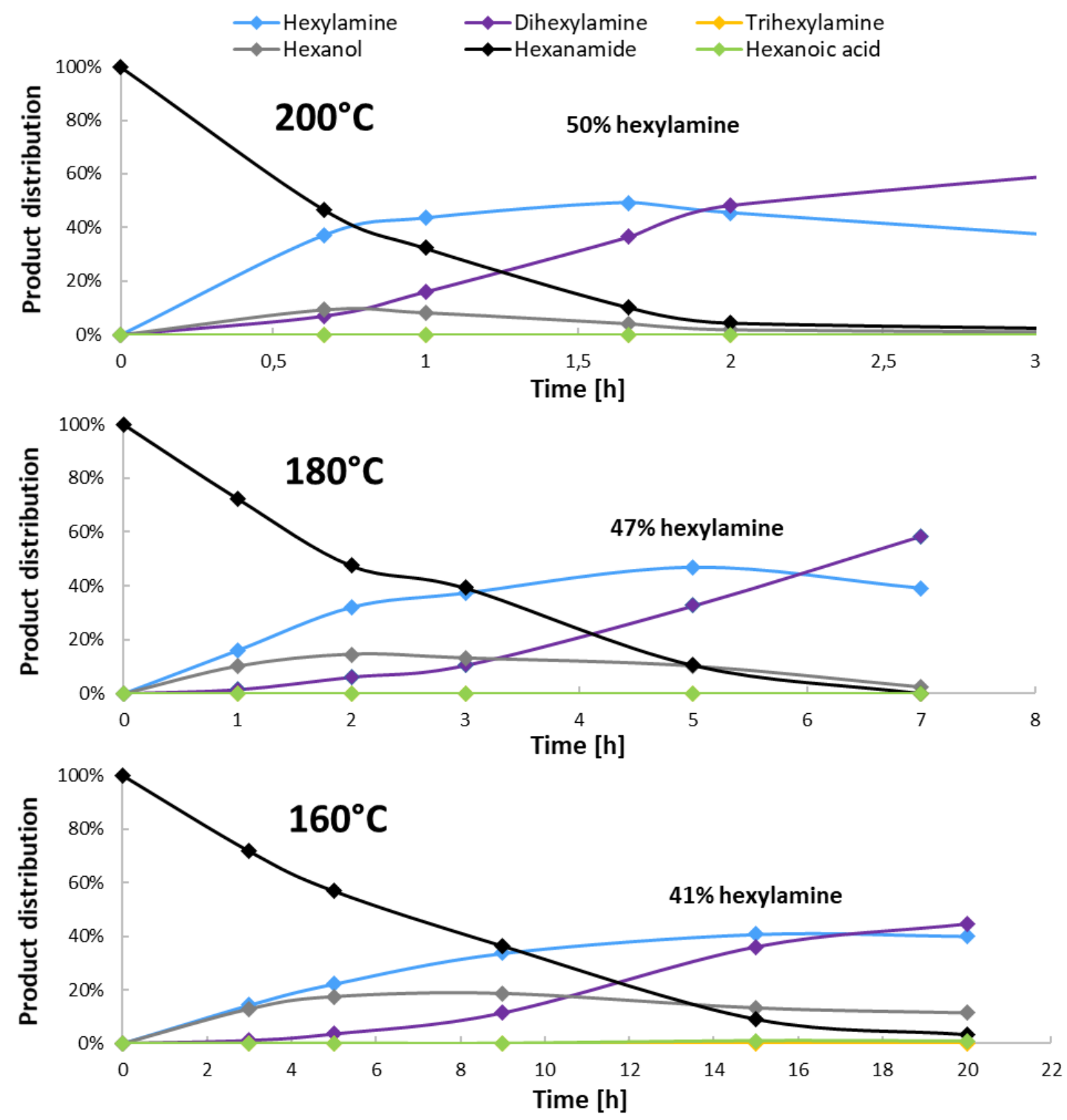

Figure 4 - Time profiles of hydrogenation of hexanamide at different temperatures: (top) $200^{\circ} \mathrm{C}$, (middle) $180^{\circ} \mathrm{C}$ and (bottom) $160^{\circ} \mathrm{C}$. Reaction conditions: hexanamide (1 mmol), 50 bar $\mathrm{H}_{2} ; 0.5$ bar $\mathrm{NH}_{3}, 5 \mathrm{~mol} \% \mathrm{Ru}\left(\mathrm{RuWO}_{\times} / \mathrm{SiO}_{2}-\mathrm{Ca}^{2+}\right)$, undecane $(20 \mu \mathrm{L})$, CPME $(10 \mathrm{~mL})$

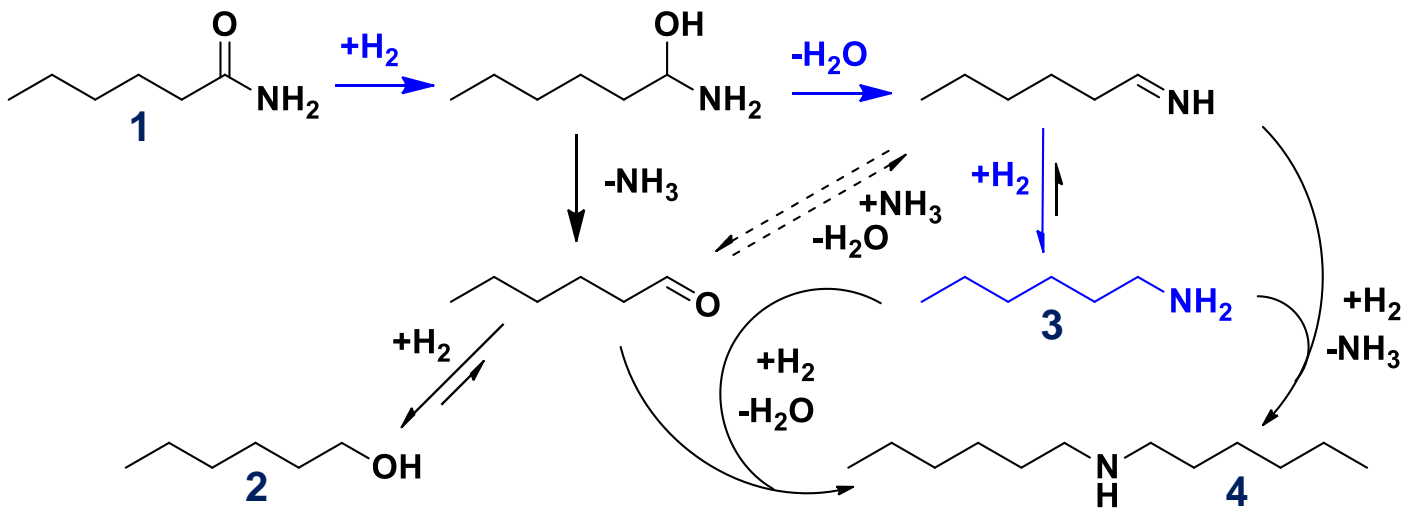

Figure 5 - Reaction network of the hydrogenation of hexanamide with RuWO ${ }_{x}$-catalyst. 
In order to further increase the primary amine yield, the ammonia and hydrogen pressure were optimized. As one might expect, the addition of ammonia increases the selectivity for hexylamine (3), since more alcohol is converted to hexylamine (3) and secondary amine formation is hindered. On the other hand, compared to the amide, ammonia is preferentially adsorbed on the catalyst and therefore it lowers the catalytic activity of $\mathrm{RuWO} \mathrm{XSiO}_{2}-\mathrm{Ca}^{2+}$. Thus, there is a clear trade-off between selectivity and activity (Figure 6). Assuming a first order reaction (Figure $S$ 8), we attempted to determine the reaction order in $\left[\mathrm{NH}_{3}\right]$ (Figure $\mathrm{S} 8$ - $S$ 11). It appears that the relation between $\ln \left(\mathrm{V}_{\text {init }}\right)$ and $\ln \left(\left[\mathrm{NH}_{3}\right]\right)$ is not linear. At low concentrations of ammonia ( $\mathrm{P}_{\mathrm{NH} 3}$ between $0.5-1$ bar) the reaction order is -0.3 , whereas at higher concentrations of ammonia $\left(\mathrm{P}_{\mathrm{NH} 3}>2\right.$ bar) the reaction order is approximately -0.9 . We expect that the influence of amine products is similar to the influence of ammonia. However, the amine concentration is very low in comparison with the concentrations of ammonia. Therefore, the inhibiting effect of amine products is probably limited.

Since it was our goal to obtain the highest possible primary amine yield under safe and ecofriendly conditions, we selected 6 bar $\mathrm{NH}_{3}(=4.5 \mathrm{M}$ of ammonia in CPME at room temperature, determined by weight) as ideal, with $77 \%$ hexylamine (3) yield $(88 \%$ conversion, $88 \%$ selectivity). This, to our knowledge, is already better than the best available results for bimetallic catalysts described in literature, as described by Beamson et al. (2010) and Hirosawa et al. (1996). ${ }^{12,20}$ In an industrial set-up, controlled addition of ammonia is a powerful tool to steer towards the desired ratio of primary vs secondary amines, since secondary amines are in some cases even more valuable than primary amines, e.g. dimethylamine. ${ }^{39}$ Excess of ammonia can be easily recycled, e.g. by degassing and cooling to liquid ammonia.

Whereas ammonia is applied to steer the selectivity, hydrogen mostly has an influence on the hydrogenation rate (combined with 6 bar $\mathrm{NH}_{3}$ ). Figure $\mathrm{S} 7$ in the Supporting Information shows that 25 bar $\mathrm{H}_{2}$ suffices to obtain an acceptable hydrogenation rate. ${ }^{39}$ 

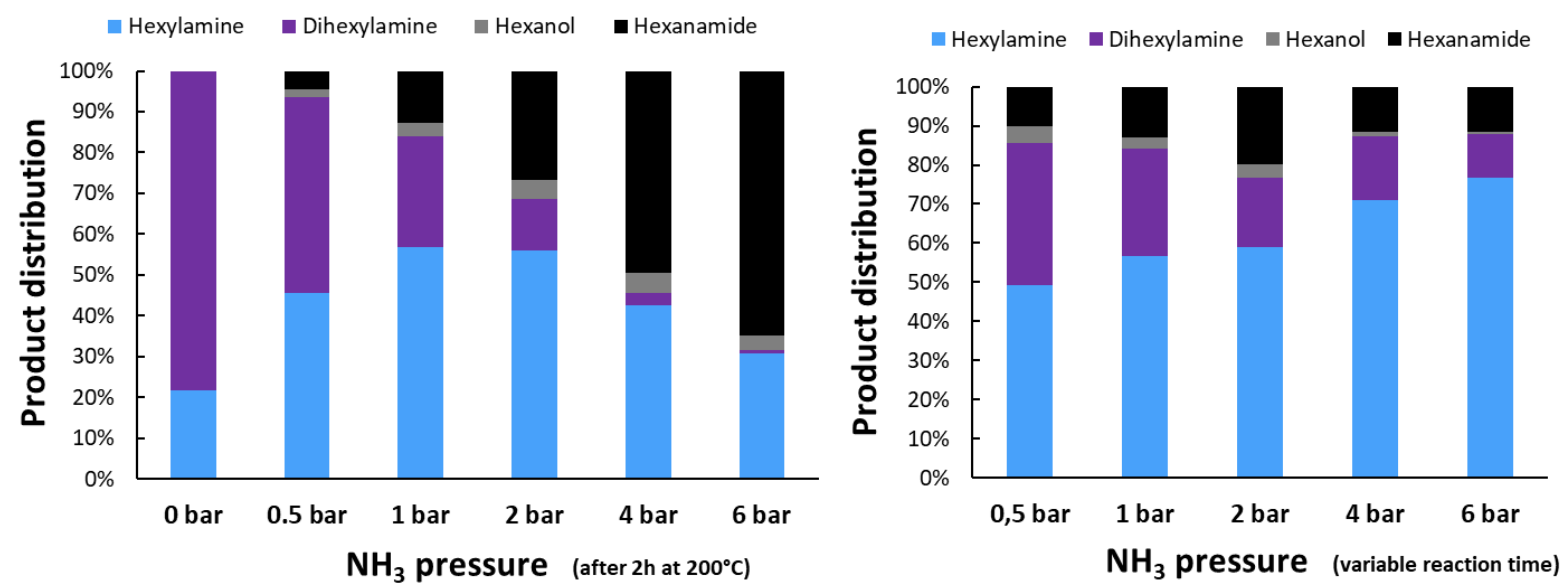

Figure 6 - Variation of the ammonia pressure in hydrogenation experiments of hexanamide: (left) fixed reaction time of $2 \mathrm{~h}$; (right) variable reaction time, with $\sim 90 \%$ conversion. Reaction conditions: hexanamide $(1 \mathrm{mmol}), 200^{\circ} \mathrm{C}, 50$ bar $\mathrm{H}_{2}, 5 \mathrm{~mol} \% \mathrm{Ru}$ $\left(\mathrm{RuWO}_{x} / \mathrm{SiO}_{2}-\mathrm{Ca}^{2+}\right)$, undecane $(20 \mu \mathrm{L})$, CPME $(10 \mathrm{~mL})$.

With 6 bar of ammonia to control the primary amine selectivity, the contribution of a basic catalyst support fades away. In Figure 7, RuWO on fumed $\mathrm{SiO}_{2}$ is compared with basic cation loaded $\mathrm{SiO}_{2}$ and spinel $\left(\mathrm{MgAl}_{2} \mathrm{O}_{4}, \mathrm{CaAl}_{2} \mathrm{O}_{4}\right)$ supports. Whereas $\mathrm{RuWO}_{x} / \mathrm{SiO}_{2}$ has a hexylamine (3) selectivity of $84 \%$, a selectivity of $85-90 \%$ is observed for RuWO on a basified support (at $\sim 90 \%$ conversion). Even more interesting is the behaviour of RuWO $/$ spinel. Wielding a spinel support drastically increased the catalytic activity, with $83 \%$ hexylamine (3) yield at full conversion for $\mathrm{RuWO} \mathrm{O}_{x} / \mathrm{MgAl}_{2} \mathrm{O}_{4}$ (initial TOF of $2.2^{*} 10^{-4} \mathrm{~s}^{-1}$ ). To investigate this difference in reaction rate, $\mathrm{RuWO}{ }_{x} / \mathrm{SiO}_{2}$ and $\mathrm{RuWO} \mathrm{O}_{x} / \mathrm{MgAl}_{2} \mathrm{O}_{4}$ both were characterized with $\mathrm{N}_{2}$-physisorption and TEM(-EDX) (see Supporting Information). It appeared that, while $\mathrm{RuWO}_{\star} / \mathrm{SiO}_{2}$ has the highest BET surface area $\left(395 \mathrm{~m}^{2} / \mathrm{g}\right.$, vs $159 \mathrm{~m}^{2} / \mathrm{g}$ in case of $\left.\mathrm{RuWO}_{\mathrm{x}} / \mathrm{MgAl}_{2} \mathrm{O}_{4}\right), \mathrm{RuWO} \times \mathrm{MgAl}_{2} \mathrm{O}_{4}$ has the smallest $\mathrm{Ru}$ particle size, resulting in a higher catalytic activity due to an increased specific metal surface (Ru particle diameter of 1.5 - $2 \mathrm{~nm}$ vs 2 - $3 \mathrm{~nm}$ for $\left.\mathrm{RuWO}_{\star} / \mathrm{SiO}_{2}\right)$. A similar effect was observed when comparing the performance of $\mathrm{Ru} / \mathrm{C}$ with $\mathrm{Ru} / \mathrm{SiO}_{2}\left(\right.$ Figure $1,<2 \mathrm{~nm}$ vs 2 - $3 \mathrm{~nm}$ for $\mathrm{Ru} / \mathrm{SiO}_{2}$ ). The TEM-EDX data also show that $\mathrm{W}$ is very evenly distributed over the entire surface, not making clusters like Ru does. 


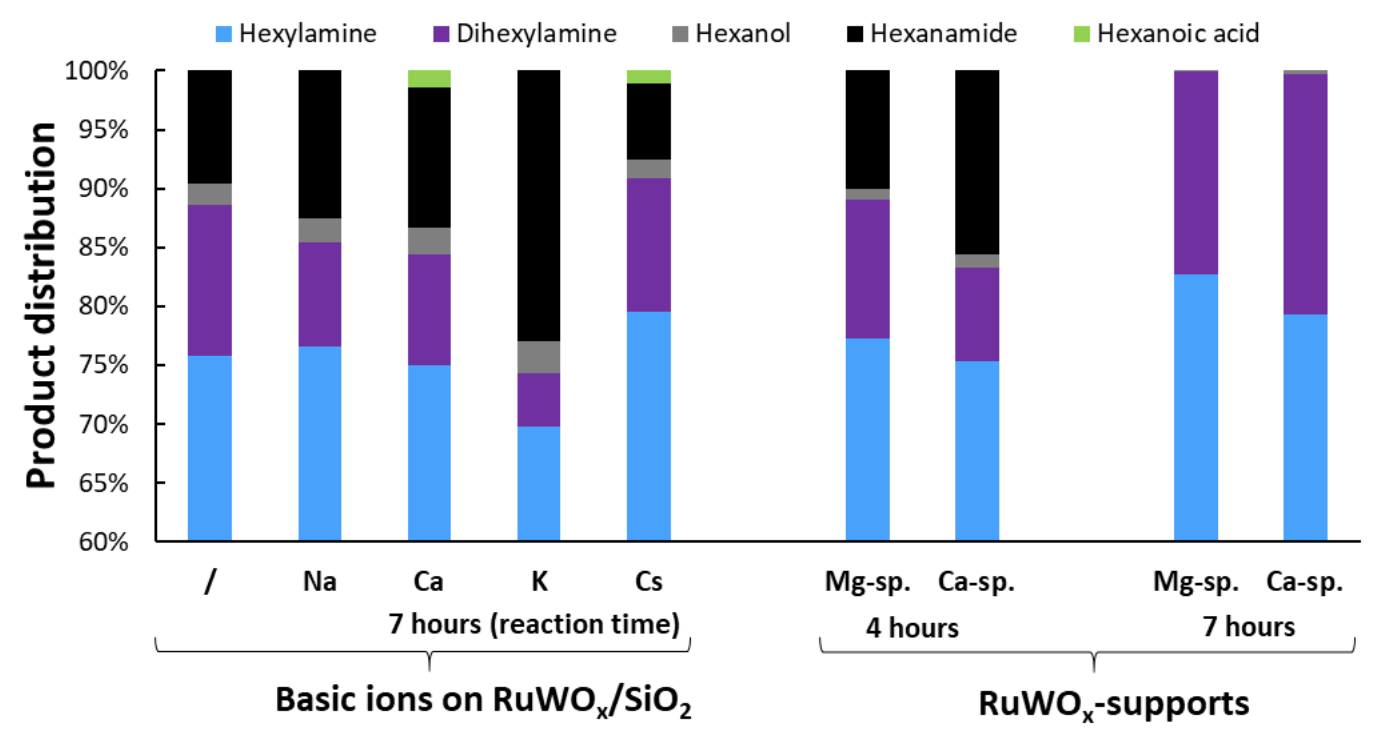

Figure 7 - Catalytic screening of $\mathrm{RuWO}_{x}$ on various supports: (left) $\mathrm{SiO}_{2}$ vs Na-, Ca-, K- \& Cs-loaded $\mathrm{SiO}_{2}$ (7 h); (right) Mg- vs Ca-spinel ( $4 \mathrm{~h} \& 7 \mathrm{~h})$. Reaction conditions: hexanamide $(1 \mathrm{mmol}), 200^{\circ} \mathrm{C}, 50$ bar $\mathrm{H}_{2}, 6$ bar $\mathrm{NH}_{3}, 7 \mathrm{~mol} \% \mathrm{Ru}$, undecane $(20 \mu \mathrm{L})$, CPME $(10 \mathrm{~mL})$.

To investigate the stability of $\mathrm{RuWO} \times \mathrm{MgAl}_{2} \mathrm{O}_{4}$, a recycling test was performed along with ICP analysis and XRD of both fresh and used catalyst. The recycling test showed that RuWO ${ }_{x} / \mathrm{MgAl}_{2} \mathrm{O}_{4}$ can be used at least 5 times without losing any catalytic activity nor selectivity (the same goes for $\mathrm{RuWO}_{\mathrm{x}} / \mathrm{SiO}_{2}$, Figure $\mathrm{S} 12$ ); after each run, a nearly full conversion with a selectivity for the primary amine of approximately $80 \%$ was observed. This is a rather interesting observation since literature states that the selectivity of Beamson's RuMo catalyst for the primary amine drops significantly after three runs. ${ }^{12}$ The high stability of this RuWO -catalyst could be confirmed by ICP; both Ru and W content in the mixture after reaction were below the detection limits (1 ppb), which represents a leaching below $0.005 \%$ and $0.02 \%$ respectively. The recorded XRD patterns do not show any $\mathrm{Ru}$ peaks and essentially remain the same, once again illustrating the high stability of the catalyst (no sintering, Ru nanoparticles are too small to be detected by XRD, Figure $S$ 17). Since the catalyst does not show signs of deactivation, we are unable to calculate a turnover number (TON) until catalyst deactivation. However, a complete conversion can be reached with even just $0.5 \mathrm{~mol} \%$ of $\mathrm{Ru}$, which means that at the end of a single run, the TON amounts to at least 200.

A last key factor that requires investigation, is the (Lewis) acidity of the catalyst. It has been proposed that these bimetallic compounds are excellent catalysts for the hydrogenation of amides because the metal oxide promotor presents Lewis acid sites. These Lewis acids sites help with the adsorption of amides to the surfaces. As a result, the interface PGM-metal oxide acquires a high catalytic activity. To investigate the (Lewis) acidity of the catalyst, $\mathrm{NH}_{3^{-}}$ TPD was performed. The data clearly show that there are two types of (Lewis) acid sites on the catalyst's surface (Figure 8). Based on the cumulative amount of $\mathrm{NH}_{3}$ adsorbed to the 
surface, we calculated that there are $0.055 \mathrm{mmol}$ acid sites per $\mathrm{g}$ of catalyst. This is approximately the same as the amount of tungsten per $\mathrm{g}$ of catalyst. It is logical to assign these acid sites to the tungsten species, since the catalytic support is typically basic $\left(\mathrm{MgAl}_{2} \mathrm{O}_{4}\right.$ spinel). The data thus suggest a very high, nearly monoatomic dispersion of tungsten. This was also suspected after analysing the TEM data. In literature, similar observations have been made for Mo, which is chemically similar to W. ${ }^{44}$

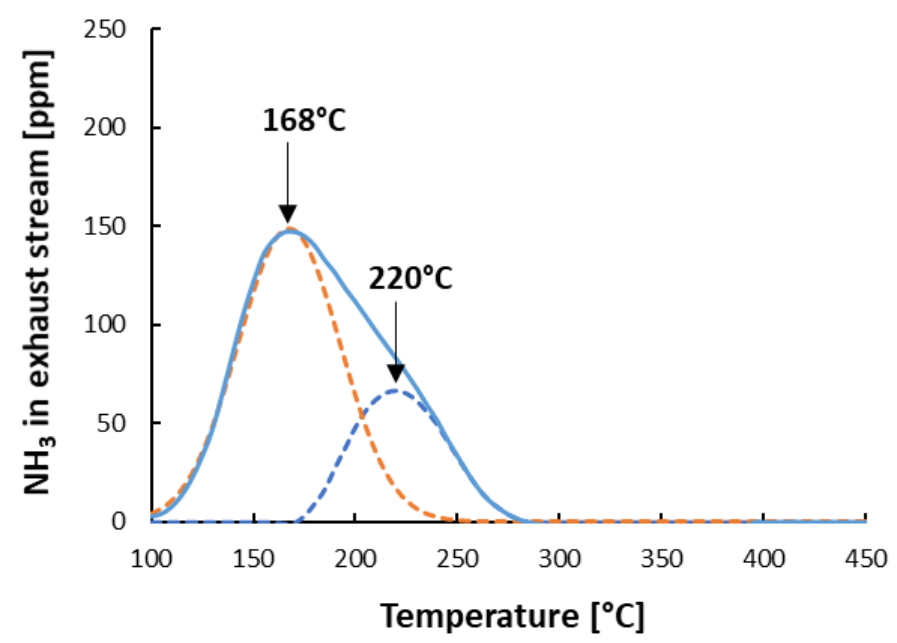

Figure $8-\mathrm{NH}_{3}$-TPD with $\mathrm{RuWO} / \mathrm{MgAl}_{2} \mathrm{O}_{4}$-catalyst. After a phase of $\mathrm{NH}_{3}$ adsorption $100^{\circ} \mathrm{C}$ and flushing the catalyst with pure $\mathrm{N}_{2}$, the catalyst bed was gradually heated $\left(5^{\circ} \mathrm{C} / \mathrm{min}\right)$ and the actual desorption takes place. The $\mathrm{NH}_{3}$ exhaust was monitored.

Finally, a substrate scope investigation was performed to illustrate the range of applicability (Table 1 \& supporting information). High yields of the corresponding primary amines were obtained for all aliphatic monofunctional primary amides (entries 1-5). The high yields and selectivities are consistently obtained for chain lengths between C3 and C12. Hydrogenation experiments with primary $\alpha, \omega$-diamides produced some interesting results; short bifunctional molecules tend to follow a deamination/decarbonylation pathway resulting in monofunctional primary amides, which react further as expected (entry 6 ). In case of longer $\alpha, \omega$-diamides, each amide group reacts more independently. However, once an 'amino-amide' of appropriate chain length is formed, the molecule easily performs an intramolecular transamination resulting in a cyclic secondary amide. Only small amounts of the $\alpha, \omega$-diamine can be detected. This explains why the results for adipamide and caprolactam are virtually the same, with a yield of $85 \%$ azepane..$^{40}$ In these two reactions, hexylamine is the main side product, presumably formed after hydrogenolysis of the azepane ring. Such a cyclization reaction was not observed for the C10 diamide, viz. decanediamide (entry 9). Acyclic secondary and tertiary amides with very short $\mathrm{N}$-substituents were reduced as well, although this probably does not proceed via a direct hydrogenation of the secondary/tertiary amides themselves (entries $10 \& 12$ ); rather ammonolysis will take place first, yielding primary amides which react further to primary amines. The short amines (e.g. methyl-, dimethylamine) were not detected due to their very low boiling points (e.g. $-6^{\circ} \mathrm{C}$ and $7^{\circ} \mathrm{C}$ 
respectively). If the $\mathrm{N}$-substituent is more bulky, the ammonolysis does not proceed, leading to a low hydrogenation rate (entry 11). More activated tertiary amides such as $\mathrm{N}$ acetylmorpholine, can be easily hydrogenated as well (entry 13). Such molecules have an increased preference for a C-N cleavage over C-O cleavage (45\% morpholine yield). At $200^{\circ} \mathrm{C}$, however, the morpholine ring itself isn't stable. Besides morpholine, diethylamine and some minor side product, the hydrogenation of $\mathrm{N}$-acetylmorpholine resulted in a large amount of ethanol and ethylamine (see supporting information).

Table 1 - Substrate scope investigation with $\mathrm{RuWO}_{\mathrm{x}} / \mathrm{MgAl}_{2} \mathrm{O}_{4}$.

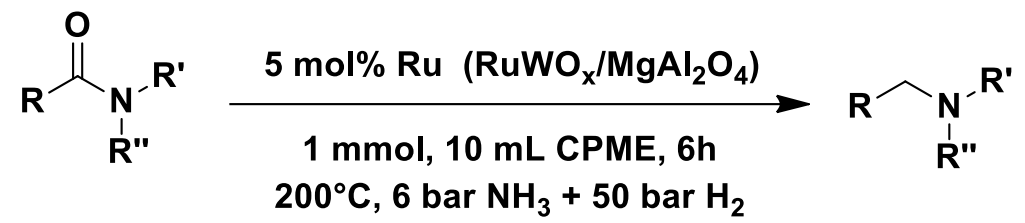

Substrate


Additionally, we discovered that secondary amines are not necessarily dead-end products. With nearly any commercial PGM supported on carbon, we were able to cleave dihexylamine (4) into hexylamine (3) with 62\% yield (Ru \& Pt on carbon supports, Figure 10). The reverse reaction with hexylamine $(3)$ showed that this is the equilibrium position between mono- and dihexylamine at $200^{\circ} \mathrm{C}, 10$ bar $\mathrm{H}_{2}, 6$ bar $\mathrm{NH}_{3}(=4.5 \mathrm{M}$ of ammonia) in CPME (Figure 9 \& Figure $S$ 20). The capability to valorize secondary(/tertiary) amines opens up many possibilities. First, $100 \%$ yield of the primary amine is in theory possible. However, this would require a continuous isolation of the primary amine from the secondary amine. Secondly, one can opt to perform the difficult amide hydrogenation in the absence of ammonia to selectively obtain the secondary amine (Figure 6) and perform an ammonolysis afterwards. Although a one-step hydrogenation process provides higher yields, the two-step process would drastically increase the hydrogenation rate and replace a single hydrogenation process at elevated pressure, by a combined process operating under milder conditions. To our knowledge, the ammonolysis of secondary or tertiary amines has only been reported once, viz. by Olin et al. in $1937 .{ }^{41}$ In their work, a yield of approximately $33 \%$ monobutylamine could be obtained from dibutylamine with a $\mathrm{MnO}_{x} / \mathrm{C}$ catalyst, operating at $292^{\circ} \mathrm{C}$ starting from a molar composition of 10-1 ammonia-dihexylamine.

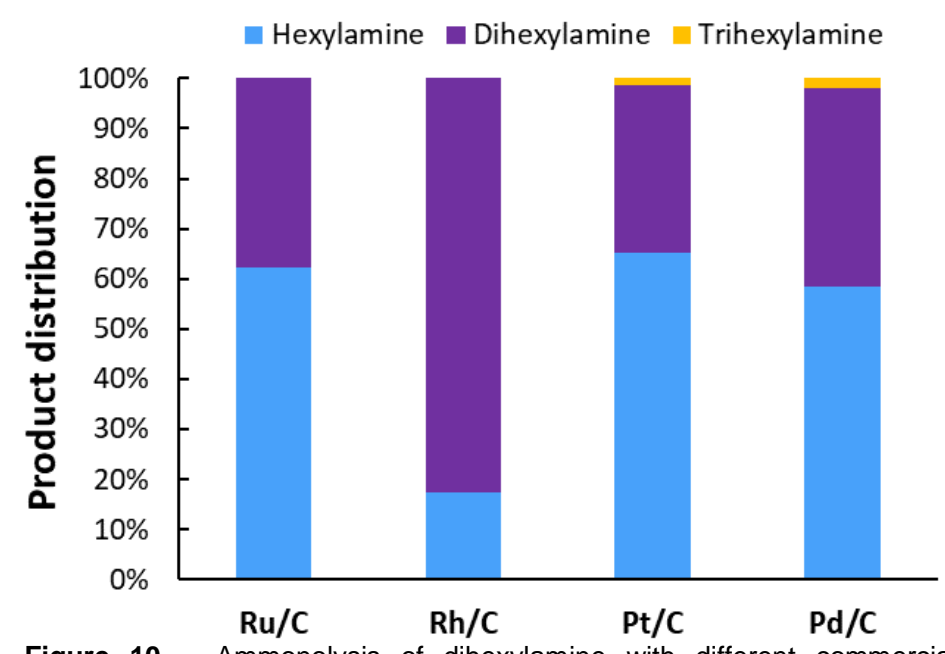

Figure 10 - Ammonolysis of dihexylamine with different commercial PGM/C. Reaction conditions: hexanamide $(1 \mathrm{mmol}), 200^{\circ} \mathrm{C}, 10$ bar $\mathrm{H}_{2}$, 6 bar $\mathrm{NH}_{3}, 5 \mathrm{~mol} \% \mathrm{Ru}$, undecane $(20 \mu \mathrm{L})$, CPME (10 mL), $5 \mathrm{~h}$.

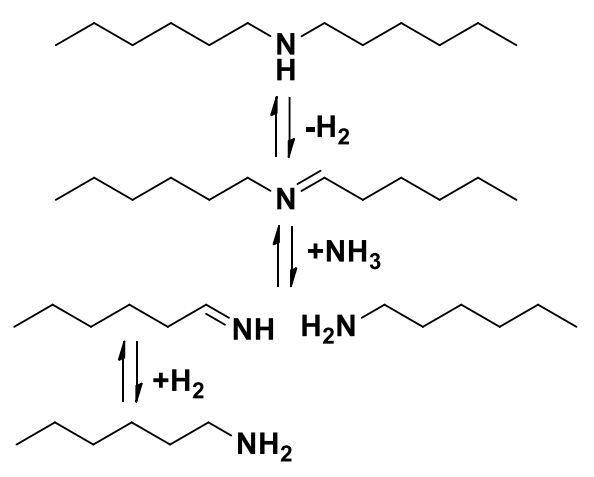

Figure 9 - Proposed reaction scheme of the ammonolysis of secondary amines.

\section{Conclusion}

In conclusion, our new and relatively cheap ruthenium-tungsten bimetallic catalyst performed excellently for the hydrogenation of aliphatic acyclic primary amides, such as hexanamide (1). Reactions were conducted in CPME. Despite the fact that CPME slightly lowers the selectivity for the primary amine, this benign and green alternative is a major improvement when compared to the commonly used toxic solvents such as DME, dioxane and hexane. It is also very stable, safe to work with and ensures an efficient product workup. 
To improve the primary amine selectivity, we explored the use of a strongly basic support (e.g. a spinel), and the use of $\mathrm{NH}_{3}$ partial pressure; the latter option is most effective. At relatively high $\mathrm{NH}_{3}$ pressures, the additional effect of a basic support is noticeable but small. After a further optimization, a yield of up to $83 \%$ of hexylamine (3) could be obtained with RuWO $\times \mathrm{MgAl}_{2} \mathrm{O}_{4}$ at $200^{\circ} \mathrm{C}$, with 50 bar $\mathrm{H}_{2}$ and 6 bar $\mathrm{NH}_{3}$ (= $4.5 \mathrm{M}$ of ammonia), using $5 \mathrm{~mol} \% \mathrm{Ru}$ after $6 \mathrm{~h}$ in CPME (initial TOF of $2.2^{*} 10^{-4} \mathrm{~s}^{-1}$ ). This green catalytic system is thus a significant improvement in comparison with current technologies for the hydrogenation of aliphatic acyclic primary amides. Finally, RuWO -catalysts were proven to be very robust and applicable on a wide range of primary amides.

\section{Acknowledgements}

The authors appreciate the assistance of Karel Duerinckx, Free De Schouwer \& Annelies Vandekerkhove, Koen Adriaensen, Guangxia Fu, Cherry Cheung, Carlos Marquez, Thomas Cuypers, Paul Van der Aerschot and Cédric Van Goethem with ${ }^{1} \mathrm{H}$ NMR, pressure reactors, spinel synthesis, $\mathrm{N}_{2}$ physisorption, $\mathrm{NH}_{3}$ temperature programmed desorption, ICP-OES measurements, $\mathrm{NH}_{3}$ set-up, technical support and TEM-EDX imaging. We also thank the financing of the Hercules fund (AKUL/13/19) and the generous support of Prof. Jin Won Seo (Dep. MTM, KU Leuven) for TEM-EDX. R. C. is also very grateful for his SB PhD fellowship at FWO.

\section{Reference}

(1) P. Roose, K. Eller, E. Henkes, R. Rossbacher, \& H. Höke, Amines, Aliphatic. In Ullmann's Encyclopedia of Industrial Chemistry: Wiley-VCH Verlag, Germany, 2015; pp 1-55

(2) S. A. Lawrence, Amines: Synthesis, Properties and Application: Cambridge University Press, 2004; pp 1-382

(3) A. M. Smith \& R. Whyman, Chemical Reviews, 2014, 114, 5477-5510.

(4) B. Wojcik, H. Adkins, J. Am. Chem. Soc. 1934, 56, 2407-2419.

(5) H. Adkins, Chem. Abstr. 1939, 33, 2906.

(6) A. Guyer, A. Bieler, G. Gerliczy, Helv. Chim. Acta 1955, 38, 1649-1654.

(7) T. Mitsudome, et al. Angewandte Chemie International Edition 2017, 56, 9381-9385.

(8) T. Miura, I. E. Held, S. Oishi, M. Naruto \& S. Saito, Tetrahedron Letters 2013, 54, 2674-2678.

(9) Y. Nakagawa, R. Tamura, M. Tamura \& K. Tomishige, Science and Technology of Advanced Materials 2015, 16, 14901.

(10) M. Stein \& B. Breit Angewandte Chemie International Edition 2013, 52, 2231-2234.

(11) K. Shimizu, W. Onodera, A. S. Touchy, S. M. Siddiki, T. Toyao \& K. Kon, ChemistrySelect 2016, 1, 736-740.

(12) G. Beamson, A. J. Papworth, C. Philipps, A. M. Smith \& R. Whyman, Advanced Synthesis and Catalysis 2010, 352, 869883.

(13) Y. Takeda, T. Shoji, H. Watanabe, M. Tamura, Y. Nakagawa, K. Okumura \& K. Tomishige, ChemSusChem, 2015, 8, 11701178.

(14) M. Tamura, S. Ishikawa, M. Betchaku, Y. Nakagawa \& K. Tomishige, Chemical Communications 2018, 54, 7503-7506.

(15) M. W. Duch \& A. M. Allgeier, Applied Catalysis A: General 2007, 318, 190-198.

(16) G. Beamson, A. J. Papworth, C. Philipps, A. M. Smith \& R. Whyman, Journal of Catalysis 2010, 269, 93-102.

(17) G. Beamson, A. J. Papworth, C. Philipps, A. M. Smith \& R. Whyman, Journal of Catalysis 2011, 278, 228-238.

(18) R. Burch, et al. Journal of Catalysis 2011, 283, 89-97.

(19) J. Coetzee, H. G. Manyar, C. Hardacre \& D. J. Cole-Hamilton, ChemCatChem 2013, 5, 2843-2847 
(20) C. Hirosawa, N. Wakasa \& T. Fuchikami, Tetrahedron Letters 1996, 37, 6749-6752.

(21) I. D. Dobson, European Patent EP 0286280 B1, 1988.

(22) I. D. Dobson, US patent 4937384, 1990.

(23) A. A. Smith, P. Dani, P. D. Higginson, A. J. Pettman, patent WO 2005/066112 A1, 2005.

(24) C. J. Clarke, W.-C. Tu, O. Levers, A. Bröhl \& J. P. Hallett, Chemical Reviews 2018, 118, 747-800.

(25) W. Rupilius, Journal of Oil Palm Research 2011, 23, 1222-1226.

(26) A. Corma Canos, S. Iborra \& A. Velty, Chemical Reviews 2007, 107, 2411-2502.

(27) J.-L. Dubois, A. Piccirilli, J. Magne, S. Tricoire, patent WO/2013/121151, 2013.

(28) J.-P. Lallier, F. Mantisi, J.-P. Gillet, M. Hidalgo, patent WO/2013/088013 A1, 2013.

(29) K. Visek, Amines, Fatty. In Kirk-Othmer Encyclopedia of Chemical Technology: John Wiley \& Sons, Inc., Hoboken, NJ, USA 2003, pp. 518-537.

(30) J. Becker, A. Lange, J. Fabarius \& C. Wittmann, Current Opinion in Biotechnology 2015, 36, 168-175.

(31) M. Sjöblom, L. Matsakas, P. Christakopoulos \& U. Rova, FEMS Microbiology Letters 2016, 363, 1-7.

(32) M. J. Campos Molina, R. Mariscal, M. Ojeda \& M. López Granados, Bioresource Technology 2012, 126, 321-327.

(33) K. Watanabe, N. Yamagiwa \& Y. Torisawa, Organic Process Research \& Development 2007, 11, 251-258.

(34) F. M. Kerton, R. Marriott, J. Clark, G. A. Kraus, A. Stankiewicz, Y. Kou \& P. Seidl, Alternative Solvents for Green Chemistry, RSC Green Chemistry, 2013, pp 1-350.

(35) D. Prat, A. Wells, J. Hayler, H. Sneddon, C. R. McElroy, S. Abou-Shehada \& P. J. Dunn, Green Chemistry 2015, 18, 288296.

(36) Sigma-Aldrich, Greener Solvent Alternatives (brochure), Sigma-Aldrich 2015, pp 1-4.

(37) Evonik Resource Efficiency GmbH, Product information AEROSIL 380, Evonik Resource Efficiency GmbH 2018, pp 1-2.

(38) J. P. Holmberg, E. Ahlberg, J. Bergenholtz, M. Hassellöv \& Z. Abbas, Journal of Colloid and Interface Science 2013, 407, 168-176.

(39) K. S. Hayes, Applied Catalysis A: General 2001, 221, 187-195.

(40) R. Simonnot \& S. Simmonot, patent FR1532777A, 1968.

(41) J. F. Olin, T. E. Deger \& I. M. Grosse, US patent 2192523, 1937.

(42) T. Toyao, S. M. A. H. Siddiki, Y. Morita, T. Kamachi, A. S. Touchy, W. Onodera, K. Kon, S. Furukawa, H. Ariga, K. Asakura, K. Yoshizawa \& K.Shimizu, Chem. Eur. J. 2017, 23, 14848-14859.

(43) J. Verduyckt, R. Coeck, D. E. De Vos, ACS Sustainable Chem. Eng. 2017, 54, 3290-3295.

(44) T. Fransen, P.C. Van Berge \& P. Mars, Studies in Surface Science and Catalysis, 1976,1, 405-420. 
Graphical abstract

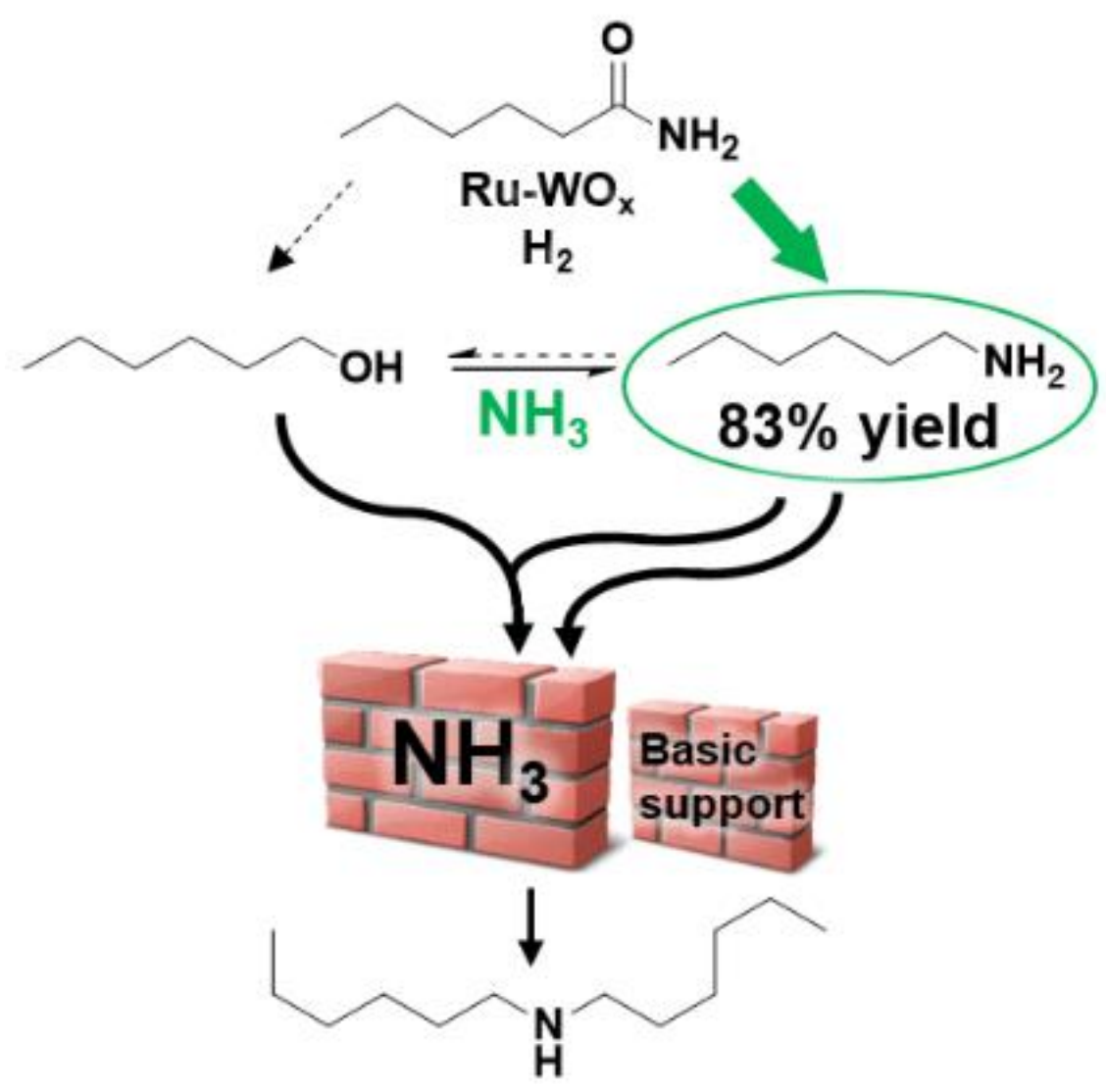




\section{Supporting information}

\section{Experimental details}

\subsection{Materials}

All chemicals were used as received: hexanamide (Tokyo Chemical Industries, >98\%), hexylamine (Sigma-Aldrich, 99\%), hexylamine (Tokyo Chemical Industries, >98\%), 1-hexanol (Sigma-Aldrich, $>99 \%$ ), trihexylamine (Alfa Aesar, 97\%), benzyl alcohol (Alfa Aesar, 99.9\%), cyclopentyl methyl ether (VWR Chemicals, 99.9\%), 1,2-dimethoxyethane (J\&K Scientific, 99.5\%), 2-methyltetrahydrofuran (Sigma-Aldrich, 99\%), tert-amyl alcohol (TCl, >98\%), tert-amyl methyl ether (Sigma-Aldrich, 97\%), undecane (Acros, 99\%), methanol-d4 (Sigma-Aldrich, 99.8\% D), $\mathrm{N}_{2}$ (Air Liquide, $\alpha 1$ ), $\mathrm{H}_{2}$ (Air liquide, N40), ammonia (Air Liquide, N38), Ru/C (5 wt\%, Alfa Aesar), Pd/C (5 wt\%, Alfa Aesar), Rh/C (5 wt\%, Alfa Aesar), Pt/C (5 wt\%, Alfa Aesar), $\mathrm{SiO}_{2}-$ Aerosil 380 (Evonik, $>99.8 \%$ ), rutile $\left(\mathrm{TiO}_{2}\right.$, nanopowder, $<100 \mathrm{~nm}$ particle size) (Sigma-Aldrich, 99.5\%), hydroxyapatite (nanopowder, $<200 \mathrm{~nm}$ particle size) (Sigma-Aldrich, >97\%), ruthenium(III) chloride hydrate (Alfa Aesar, min 38\% Ru, 99.9\% PGM basis), ammonium tungsten oxide (Alfa Aesar, 99.99+\%), platinum(II) acetylacetonate (Acros, 98\%), vanadyl(IV) acetylacetonate (Acros, 99\%), ammonium molybdate tetrahydrate (Sigma-Aldrich, 81-83\% $\mathrm{MoO}_{3}$ basis), tetraammineplatinum(II) chloride hydrate (Sigma-Aldrich, $\geq 99.99 \%$ ), rhodium chloride trihydrate (Alfa Aesar, 38.5-45.5\% Rh), ammonium metavanadate (Sigma Aldrich, 99\%), sodium hydroxide (Acros, micropearls), calcium hydroxide (Acros, 98\%), potassium hydroxide (Acros, pellets, $85 \%$ ), cesium hydroxide hydrate (Sigma-Aldrich, $>90 \%,>99.5 \%$ metal basis), adipamide (Tokyo Chemical Industries, >98\%), propionamide (J\&K Scientific, 99\%), $\mathrm{N}$-methylpropionamide (Tokyo Chemical Industries, >99\%), N,N-dimethylpropionamide (Acros, >99\%), octanamide (Tokyo Chemical Industries, $>98 \%$ ), lauramide (Tokyo Chemical Industries, $>96 \%$ ), cyclohexanecarboxamide (J\&K Scientific, >97\%), malonamide (Sigma-Aldrich, 97\%), $\varepsilon$-caprolactam (Sigma-Aldrich, >99\%), $N$ acetylmorpholine (J\&K Scientific, 98\%), hexanoyl chloride (Fisher, 97\%), azepane (Alfa Aesar, >98\%), polyvinyl alcohol (PVA, Acros, M.W. 13,000 >98\%, hydrolysed), $\mathrm{Al}\left(\mathrm{NO}_{3}\right)_{3} .9 \mathrm{H}_{2} \mathrm{O}$ (Carl Roth, $>98 \%$ ), $\mathrm{NH}_{4} \mathrm{OH}$ (Sigma-Aldrich, aqueous solution, $25 \% \mathrm{NH}_{3}$ ) and $\mathrm{Mg}\left(\mathrm{NO}_{3}\right)_{2} .6 \mathrm{H}_{2} \mathrm{O}$ (Sigma-Aldrich, 99\%).

\subsection{Product analysis and identification}

Crude reaction mixtures were analyzed by gas chromatography (GC) and nuclear magnetic resonance (NMR) spectroscopy. NMR samples were prepared by mixing $300 \mu \mathrm{L}$ of the reaction mixture with 300 $\mu \mathrm{L}$ methanol-d4. ${ }^{1} \mathrm{H}$-NMR spectra, as well as ${ }^{1} \mathrm{H},{ }^{1} \mathrm{H}$-COSY and ${ }^{1} \mathrm{H},{ }^{13} \mathrm{C}-\mathrm{HSQC}$ spectra, were recorded on a Bruker Ascend $400 \mathrm{MHz}$ spectrometer equipped with a BBO $5 \mathrm{~mm}$ atma probe and a sample case. One of the signals of CPME was suppressed by applying an adapted zgpr pulse program: $\mathrm{p} 1$ $9.75 \mu \mathrm{s}$; plw1 15W; plw9 5.7-05W; 01P on the resonance signal of CPME (around $3.27 \mathrm{ppm}$ ). Besides GC and NMR, the products were also identified by gas chromatography coupled to mass spectrometry (GC-MS) with an Agilent 6890 GC, equipped with a HP-5ms column, coupled to a 5973 MSD mass spectrometer. For a reaction with octanamide, we illustrated that the amine product can easily be isolated by destilation; after a hydrogenation reaction, an isolated yield of $0.116 \mathrm{~g}$ amines was obtained ( $91 \%$ yield, with a molar primary - secondary amine ratio of $4.1-1$; determined via NMR). 


\subsection{Catalyst characterization}

Characterized was performed by $\mathrm{N}_{2}$ physisorption, Ammonia temperature-programmed desorption $\left(\mathrm{NH}_{3}\right.$-TPD), $\mathrm{X}$-ray powder diffraction (XRD), inductively coupled plasma optical emission spectrometry (ICP-OES), transmission electron microscopy (TEM) and energy-dispersive $\mathrm{X}$-ray spectroscopy (EDX). $\mathrm{N}_{2}$ physisorption measurements were performed using a Micromeritics 3Flex surface analyzer at $-196^{\circ} \mathrm{C}$. Before the measurements, the $\sim 100 \mathrm{mg}$ samples were degassed at $140^{\circ} \mathrm{C}$ for $3 \mathrm{~h}$ under vacuum. $\mathrm{NH}_{3}$-TPD was conducted in a tubular gas phase reactor (with $200 \mathrm{mg}$ sample) connected to a Gasmet DX4000 FTIR gas analyzer. The IR data were processed with Calcmet Standard software version 12.161. XRD measurements were performed with the Malvern PANalytical Empyrean equipped with a $\mathrm{Cu} X$-ray tube and a Pixcel3D detector. Possible Ru and $\mathrm{W}$ leaching was measured by ICP using a Varian 720-ES with the Varian SPS3 sample preparation system and applying the calibration curve method. For $1 \mathrm{~mL}$ of the supernatant of the reaction mixture, the solvent was evaporated and leftover ions were redissolved in $20 \mathrm{~mL}$ aqua regia. For TEM-EDX experiments, measurements were recorded with a probe aberration corrected JEOL ARM-200F microscope equipped with a cold-FEG and operated at $200 \mathrm{kV}$. Particles were deposited on a holey carbon-coated Cu-grid. These TEM experiments also confirmed the elemental composition of the catalyst.

\subsection{Spinel synthesis and characterization}

$\mathrm{MgAl}_{2} \mathrm{O}_{4}$ (spinel) was synthesized via the procedure described by Guo et al. (2003). ${ }^{1}$ First, an aqueous solution of $2 \mathrm{wt} \%$ polyinylalcohol was prepared ( $9.3 \mathrm{~g}$ PVA, $465 \mathrm{~mL}$ water). To increase the dissolution rate of PVA, the dispersion was heated to $75^{\circ} \mathrm{C}$ and cooled when fully clear. $\mathrm{Next}, \mathrm{Mg}\left(\mathrm{NO}_{3}\right)_{2} \cdot 6 \mathrm{H}_{2} \mathrm{O}$ $(18.0 \mathrm{~g})$ and $\mathrm{Al}\left(\mathrm{NO}_{3}\right)_{3} .9 \mathrm{H}_{2} \mathrm{O}(52.7 \mathrm{~g})$ were added and dissolved, resulting in a mixture with a molar ratio Mg-AI-PVA (repeating unit) of 1-2-3. Then, ammonia solution was added under vigorous stirring until a $\mathrm{pH}$ value of 10 was reached. The resulting gel was stirred for $3 \mathrm{~h}$ at room temperature and aged afterwards overnight. The solid spinel was isolated by filtration and washed with water. Finally, the wet $\mathrm{MgAl}_{2} \mathrm{O}_{4}$ was lyophilized until a dry (non-sticky) white powder was obtained and then calcined in air at $800^{\circ} \mathrm{C}$ for $8 \mathrm{~h}\left(5^{\circ} \mathrm{C} \mathrm{min}^{-1}\right)$. The synthesized spinel was characterized by $\mathrm{N}_{2}$ physisorption and $\mathrm{X}$-ray powder diffraction (XRD).

\subsection{Most significant metal catalysts}

Table S 1 - Composition and source of most significant metal catalysts

\begin{tabular}{|c|c|c|c|}
\hline Catalyst & $\mathbf{w t} \% \mathbf{M}$ & Ratio M/M'O & Source \\
\hline $\mathrm{Pt} / \mathrm{C}-\mathrm{Pd} / \mathrm{C}-\mathrm{Rh} / \mathrm{C}-\mathrm{Ru} / \mathrm{C}$ & 5 & l & Commercial catalysts \\
\hline $\mathrm{Ru}-\mathrm{MnO}_{\mathrm{x}} / \mathrm{C}$ & 5 & 10 & Edited commercial catalyst \\
\hline $\mathrm{Ru}-\mathrm{WO}_{\mathrm{x}} / \mathrm{C}$ & 5 & 10 & Edited commercial catalyst \\
\hline $\mathrm{Pt}-\mathrm{VO}_{x} / \mathrm{HAP}$ & 7 & 1 & Homemade \\
\hline $\mathrm{Ru} / \mathrm{SiO}_{2}$ & 4 & l & Homemade \\
\hline $\mathrm{Ru}-\mathrm{WO}_{x} / \mathrm{SiO}_{2}$ & 4 & 8 & Homemade \\
\hline $\mathrm{Ru}-\mathrm{WO}_{\times} / \mathrm{SiO}_{2}-\mathrm{Ca}^{2+}$ (or other ions) & 4 & 8 & Homemade \\
\hline $\mathrm{Ru}-\mathrm{WO}_{\mathrm{x}} / \mathrm{MgAl}_{2} \mathrm{O}_{4}$ & 4 & 8 & Homemade \\
\hline Ru/rutile & 4 & I & Homemade \\
\hline Ru-WO $/$ /rutile & 4 & 8 & Homemade \\
\hline
\end{tabular}




\section{Preliminary hydrogenation experiments with different noble metals}
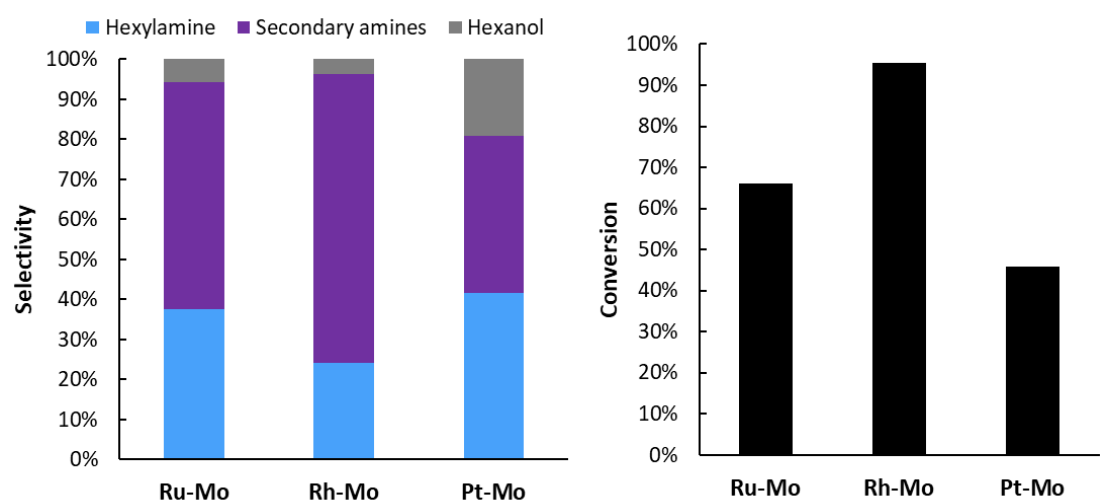

\begin{tabular}{|c|r|}
\hline \multicolumn{2}{|c|}{ Metal prices (5 April 2019) } \\
\hline $\mathrm{Ru}$ & $\sim 7,000 \mathrm{EUR} / \mathrm{kg}$ \\
\hline $\mathrm{Pt}$ & $\sim 23,000 \mathrm{EUR} / \mathrm{kg}$ \\
\hline $\mathrm{Rh}$ & $\sim 65,000 \mathrm{EUR} / \mathrm{kg}$ \\
\hline
\end{tabular}

Figure S 1 - Preliminary hydrogenation experiments with PGM-Mo catalysts on $\mathrm{SiO}_{2}$-aerosil-380 support (4 wt\% PGM, molar PGM-Mo ratio of 1). Reaction conditions: hexanamide $(1 \mathrm{mmol}), 180^{\circ} \mathrm{C}, 40$ bar $\mathrm{H}_{2}, 3 \mathrm{~mol} \% \mathrm{PGM}$, undecane $(20 \mu \mathrm{L})$, DME $(10 \mathrm{~mL}), 16 \mathrm{~h}$.

\section{Kinetic experiments in DME and CPME}
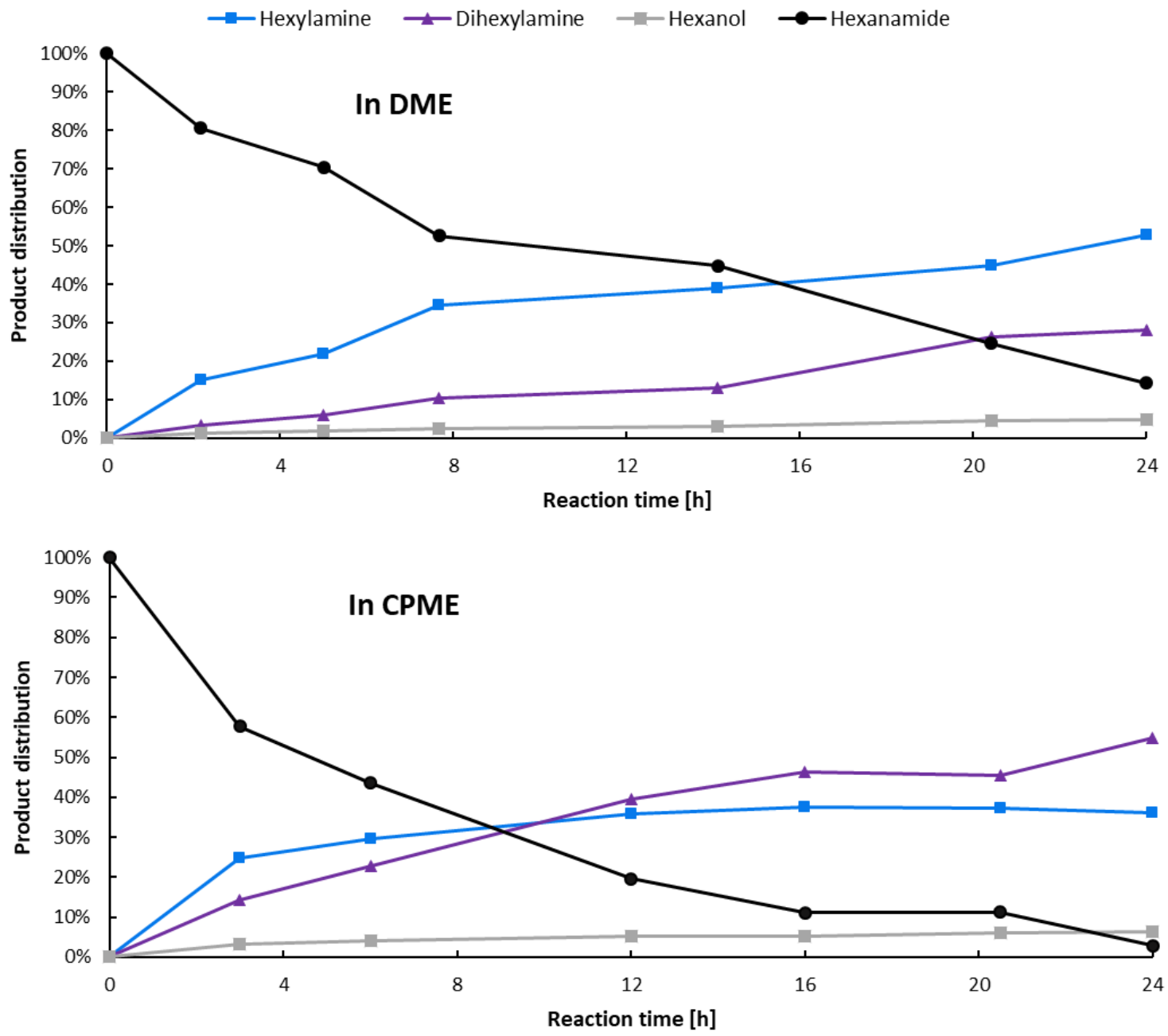

Figure $\mathbf{S} 2$ - Time profile of hydrogenation experiments in dimethoxyethane (DME, top) and cyclopentyl methyl ether (CPME, botom). Reaction conditions: hexanamide $(1 \mathrm{mmol}), 160^{\circ} \mathrm{C}, 60$ bar $\mathrm{H}_{2}, 1 \mathrm{~mol} \% \mathrm{Ru}\left(\mathrm{RuWO}_{x} / \mathrm{SiO}_{2}\right)$, undecane $(20 \mu \mathrm{L})$, solvent $(10 \mathrm{~mL})$. 


\section{Search for suitable amide hydrogenation catalyst and determining the product stability}

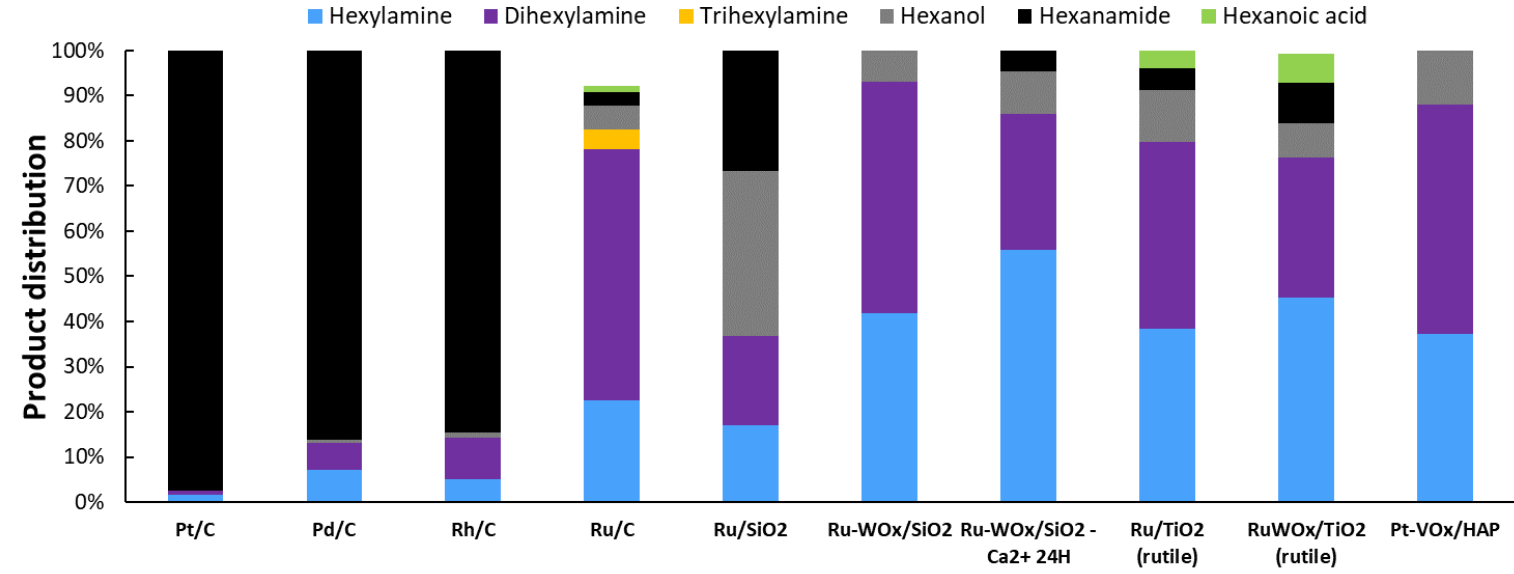

Figure S 3 - Variation of the amide hydrogenation catalyst. Reaction conditions: hexanamide $(1 \mathrm{mmol}), 180^{\circ} \mathrm{C}, 50$ bar $\mathrm{H}_{2} ; 0.5$ bar $\mathrm{NH}_{3} ; 1$ mol\% Ru (or same weight other PGM), undecane $(20 \mu \mathrm{L})$, CPME $(10 \mathrm{~mL}), 16 \mathrm{~h}$.

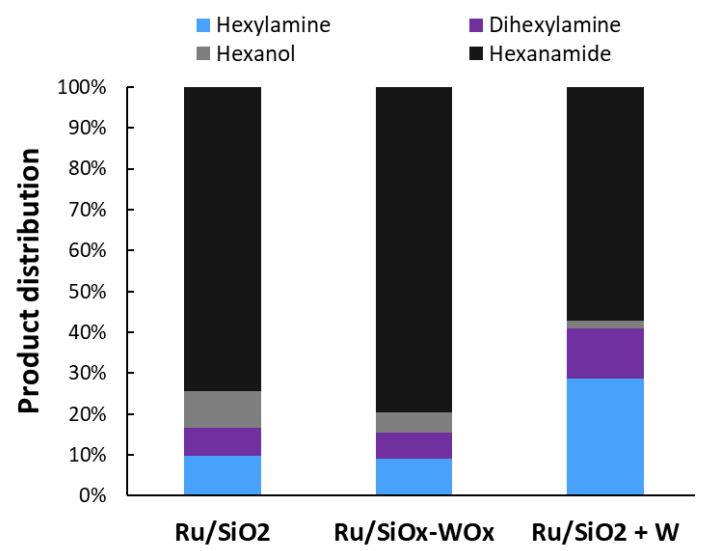

Figure S 5 - Hydrogenation experiments with $\mathrm{Ru}$ catalyst: (left) $\mathrm{Ru} / \mathrm{SiO}_{2}$, (middle) $\mathrm{Ru}$ deposited on W-modified $\mathrm{SiO}_{2}$ support and (right) $\mathrm{Ru} / \mathrm{SiO}_{2}$ with post W-deposition. Reaction conditions: hexanamide (1 mmol), $180^{\circ} \mathrm{C}, 40$ bar $\mathrm{H}_{2}, 0.5 \mathrm{~mol} \% \mathrm{Ru}$, undecane $(20 \mu \mathrm{L})$, DME $(10 \mathrm{~mL}), 16 \mathrm{~h}$.

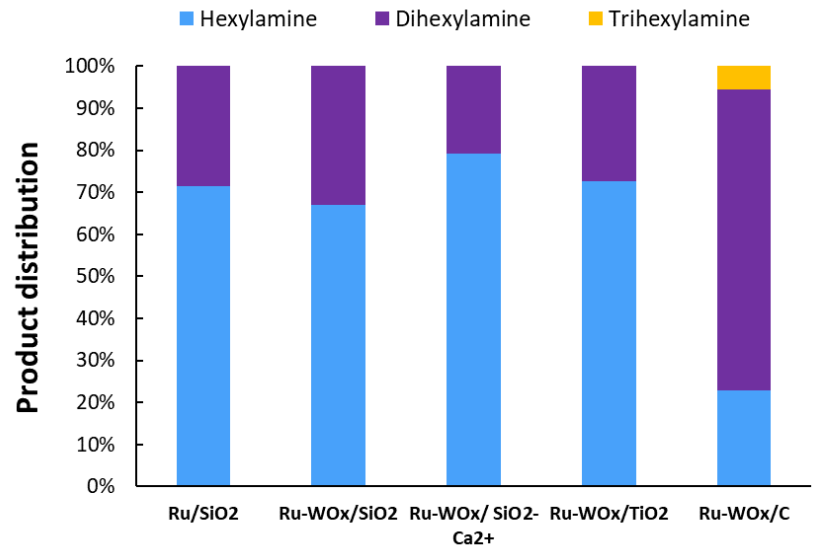

Figure S 4 - Screening of the product stability (hexylamine) in the presence of different hydrogenation catalysts. Reaction conditions: hexylamine ( $1 \mathrm{mmol}), 180^{\circ} \mathrm{C}, 50$ bar $\mathrm{H}_{2} ; 0.5$ bar $\mathrm{NH}_{3}$, $0.5 \mathrm{~mol} \% \mathrm{Ru}$, undecane $(20 \mathrm{\mu L}), \mathrm{CPME}(10 \mathrm{~mL}), 16 \mathrm{~h}$.

\section{Variation of the reaction conditions (temperature and hydrogen pressure)}

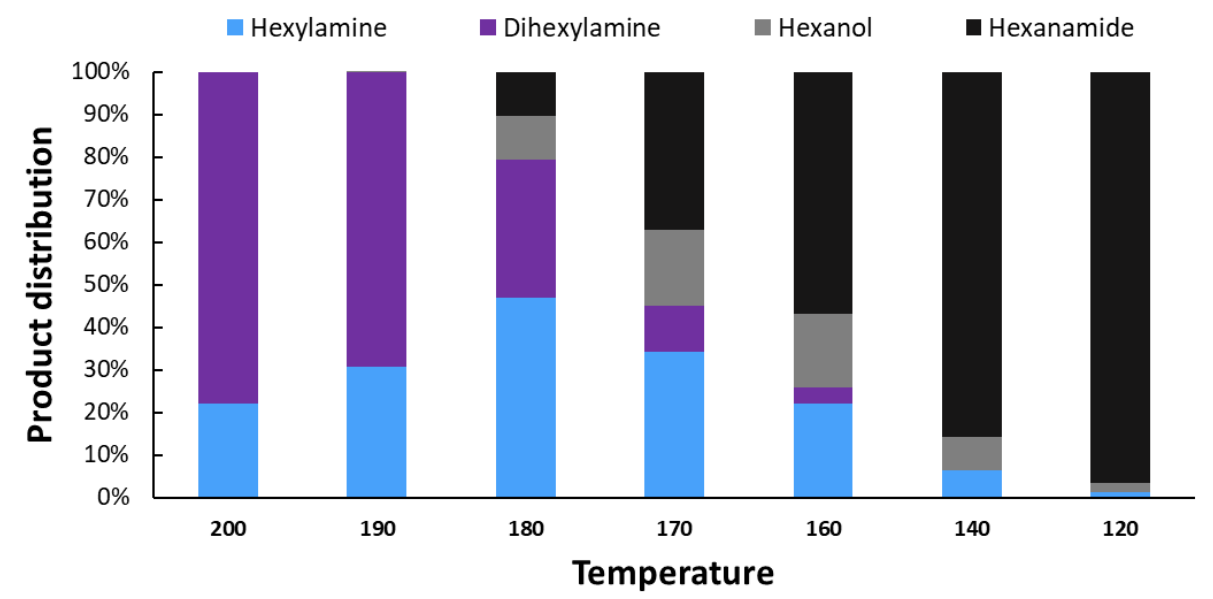

Figure $\mathbf{S} 6$ - Variation of the reaction temperature. Reaction conditions: hexanamide $(1 \mathrm{mmol})$, 50 bar $\mathrm{H}_{2} ; 0.5$ bar $\mathrm{NH}_{3}, 5 \mathrm{~mol} \% \mathrm{Ru}\left(\mathrm{RuWO}_{\mathrm{x}} / \mathrm{SiO}_{2}-\mathrm{Ca}^{2+}\right)$, undecane $(20 \mu \mathrm{L})$, CPME $(10 \mathrm{~mL}), 5 \mathrm{~h}$. 


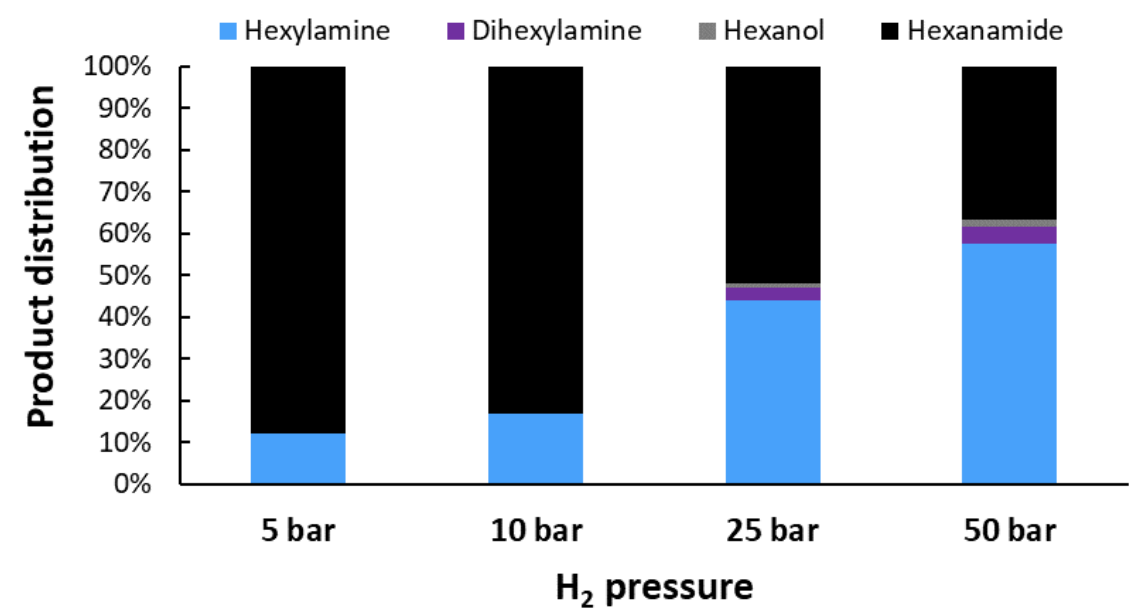

Figure $\mathbf{S} \mathbf{7}$ - Variation of the hydrogen pressure. Reaction conditions: hexanamide (1 mmol), $200^{\circ} \mathrm{C}, 6$ bar $\mathrm{NH}_{3}, 5 \mathrm{~mol} \% \mathrm{Ru}\left(\mathrm{RuWO}_{x} / \mathrm{SiO}_{2}-\mathrm{Ca}^{2+}\right)$, undecane $(20 \mu \mathrm{L})$, CPME $(10 \mathrm{~mL}), 8 \mathrm{~h}$.

\section{Kinetics - first order hydrogenation}

Under the assumption that the hydrogenation proceeds according to a first order reaction (with $\mathrm{P}_{\mathrm{H} 2}=$ constant); $\underline{d \text { [amide] }}$ $\frac{d t}{d t}=-k[$ amide $] \leftrightarrow \ln \left(\right.$ amide $\left._{t=0}\right)-\ln \left(\right.$ amide $\left._{t=t}\right)=k . t$ and the Arrhenius equation;

$k=k_{0} \cdot e^{\frac{-E a}{R \cdot T}} \leftrightarrow \ln (k)=\ln \left(k_{0}\right)-\frac{E_{a}}{R \cdot T}$

Plotting $\ln (\mathrm{k})$ derived from function (1) in function of $\mathrm{T}^{-1}$, should give a straight curve (2) if the assumption of a first order reaction is correct. This indeed appeared to be the case.

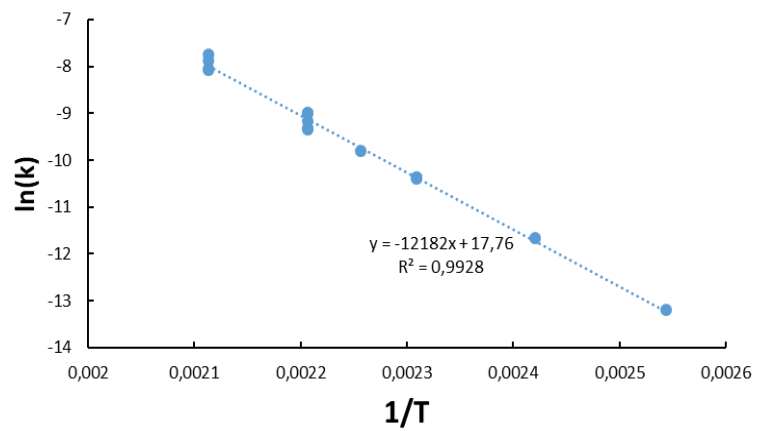

Figure $\mathbf{S} 8-\ln (\mathrm{k})$ in function of $1 / \mathrm{T}$. For the determination of $\mathrm{k}$, all experiments were performed with: hexanamide $(1 \mathrm{mmol})$, 50 bar $\mathrm{H}_{2} ; 0.5$ bar $\mathrm{NH}_{3}, 5 \mathrm{~mol} \% \mathrm{Ru}\left(\mathrm{RuWO}_{x} / \mathrm{SiO}_{2}-\mathrm{Ca}^{2+}\right)$, undecane $(20 \mu \mathrm{L})$, CPME $(10 \mathrm{~mL})$.

\section{Kinetics - influence of ammonia}

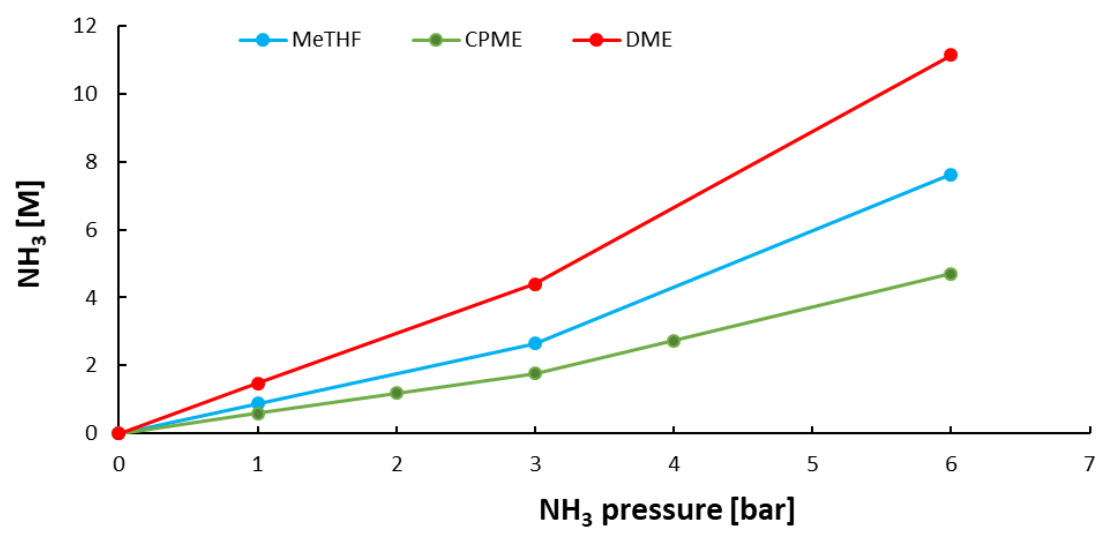

Figure S 9 - Ammonia concentration in different solvents (DME, MeTHF and CPME) as a function of the ammonia pressure. 


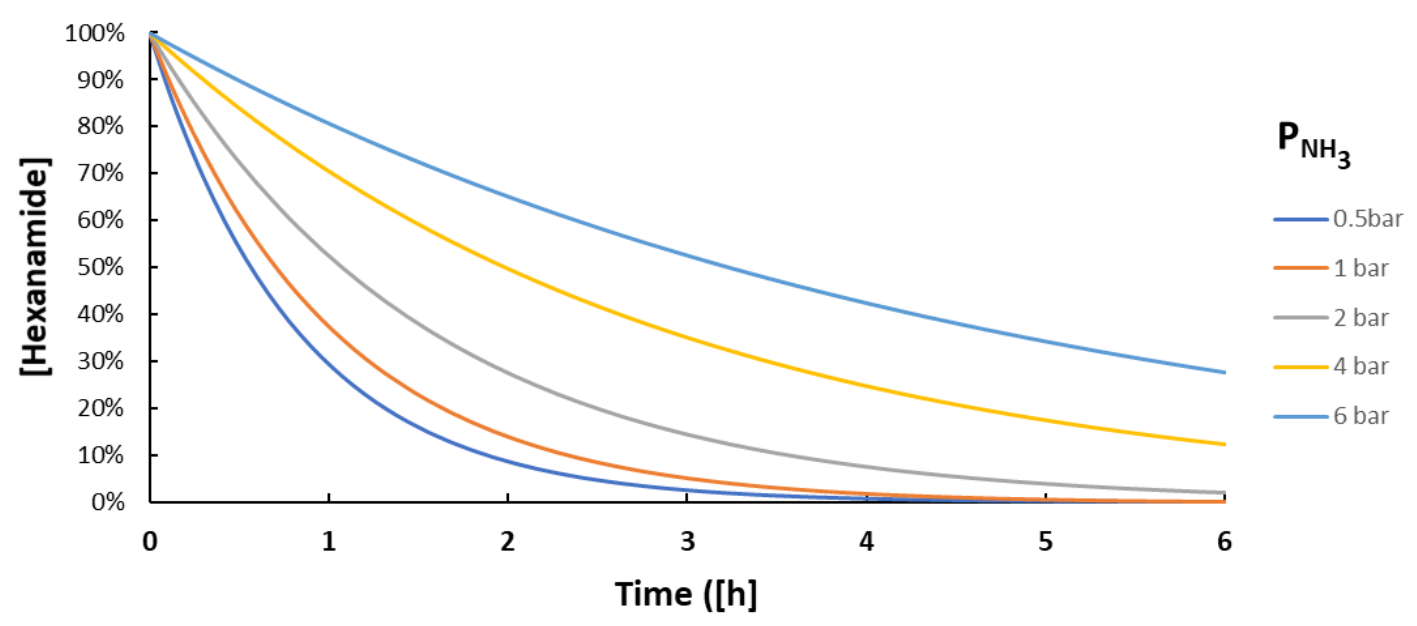

Figure S 10 - Hexanamide concentration in function of time for different ammonia pressures. Reaction conditions: hexanamide (1 mmol), $200^{\circ} \mathrm{C}, 50$ bar $\mathrm{H}_{2}, 5 \mathrm{~mol} \% \mathrm{Ru}\left(\mathrm{RuWO}_{\times} / \mathrm{SiO}_{2}-\mathrm{Ca}^{2+}\right)$, undecane $(20 \mathrm{\mu L}), \mathrm{CPME}(10 \mathrm{~mL})$.
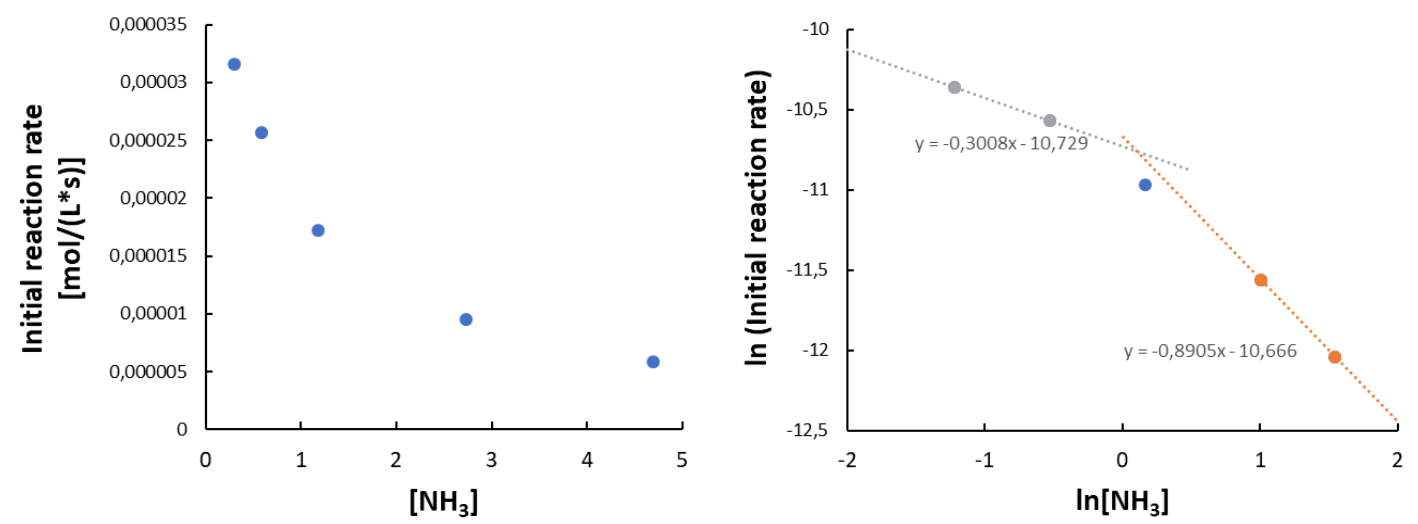

Figure S 11 - The initial reaction rate (see Figure S 10) in function of [NH3] (left) and In(initial reaction rate) i.f.o. $\ln [-\mathrm{NH} 3]$ (right).

\section{Characterization of the $\mathrm{RuWO}_{x}$-catalysts}
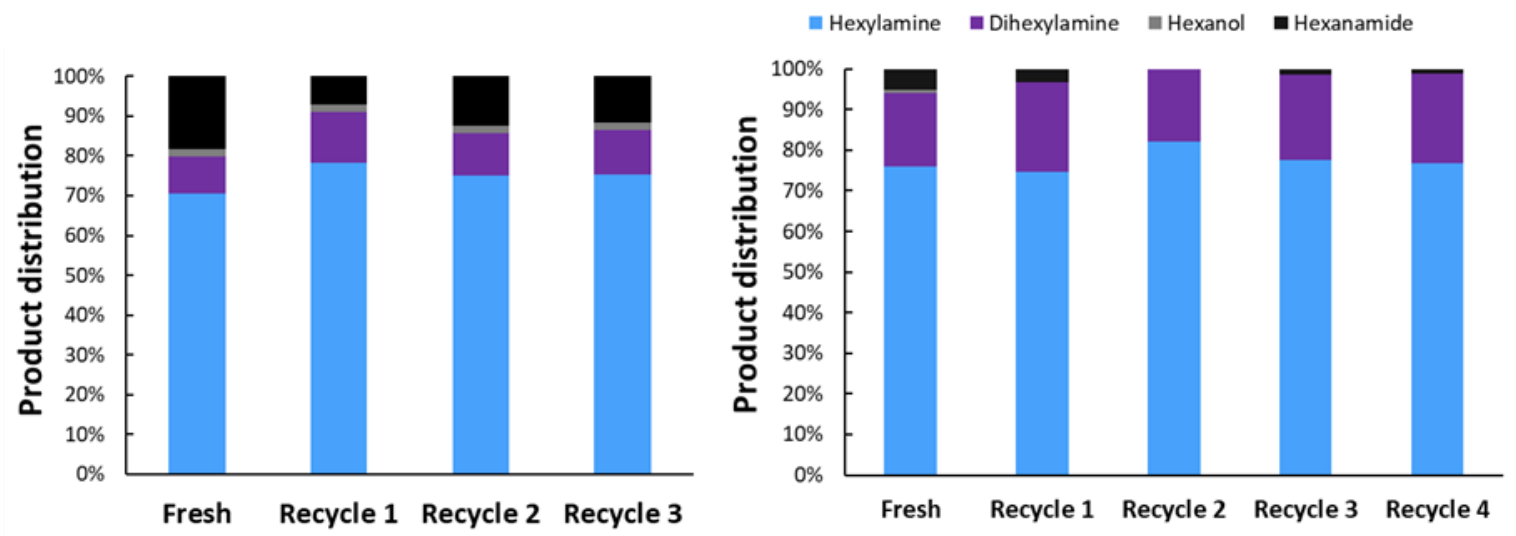

Figure S 12 - Recycling test of RuWO -catalysts: (left) RuWO $/ \mathrm{SiO}_{2}\left(7 \mathrm{~mol} \% \mathrm{Ru}\right.$ per run, 7 h) and (right) $\mathrm{RuWO}_{\times} / \mathrm{MgAl}_{2} \mathrm{O}_{4}$ (5 mol\% Ru per run, $6 \mathrm{~h}$ ). Reaction conditions: hexanamide $(1 \mathrm{mmol}), 200^{\circ} \mathrm{C}, 50$ bar $\mathrm{H}_{2}, 6$ bar $\mathrm{NH}_{3}$, undecane $(20 \mu \mathrm{L}), \mathrm{CPME}$ $(10 \mathrm{~mL})$. 

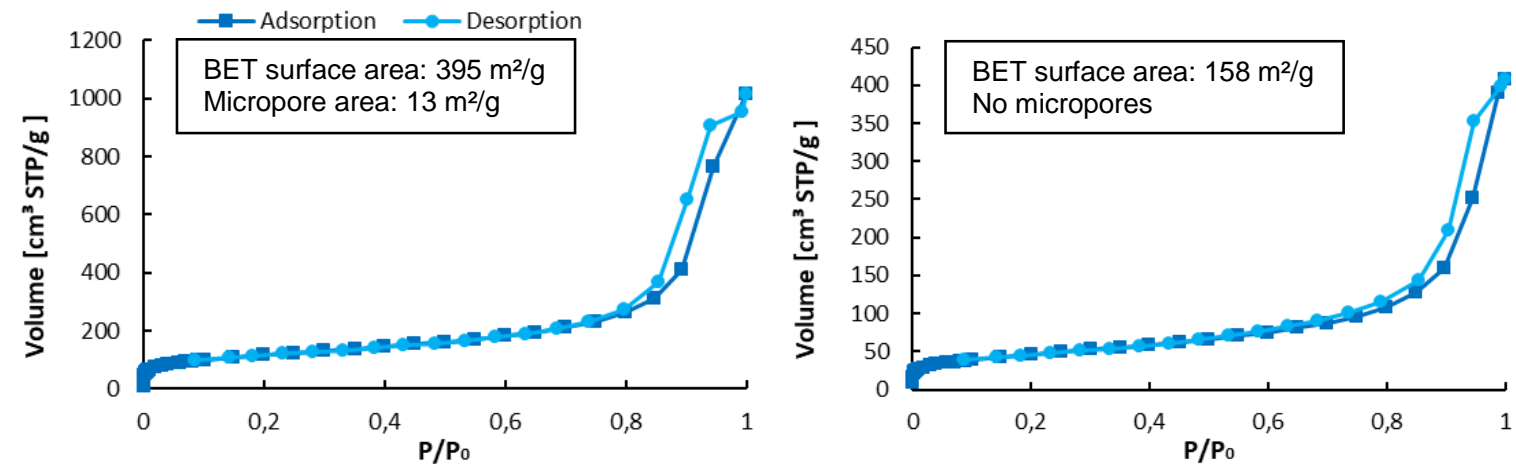

Figure $\mathrm{S} 13$ - BET surface area determination from $\mathrm{N}_{2}$-physisorption isotherm for $\mathrm{RuWO} / \mathrm{SiO}_{2}$ (left) and $\mathrm{RuWO}_{x} / \mathrm{MgAl}_{2} \mathrm{O}_{4}$ (right).

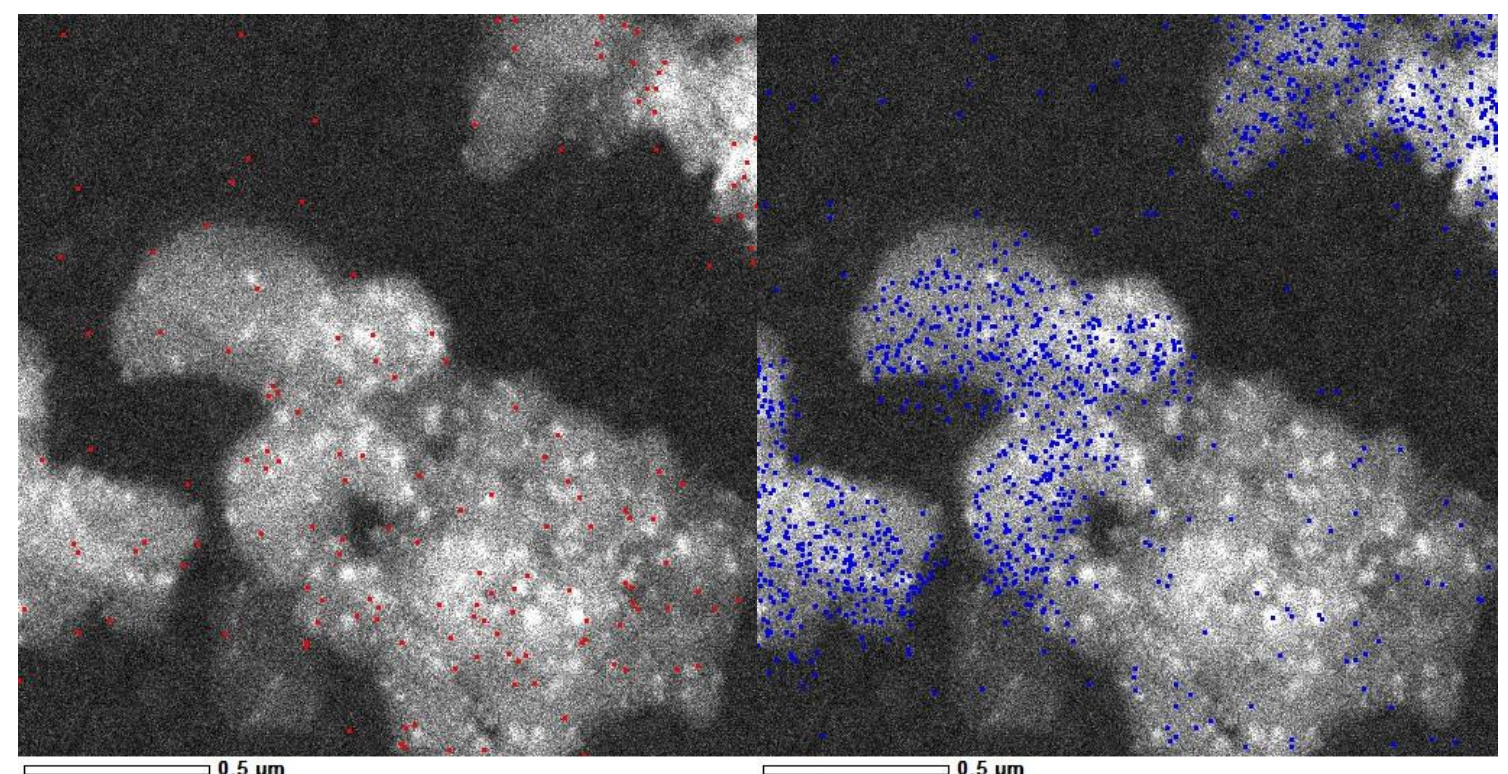

Figure S 14 - TEM-EDX image of $\mathrm{RuWO}_{\times} / \mathrm{MgAl}_{2} \mathrm{O}_{4}$ : (left) overlap with the detected ruthenium (white spots = ruthenium particles); (right) overlap with the detected tungsten (homogeneously distributed).

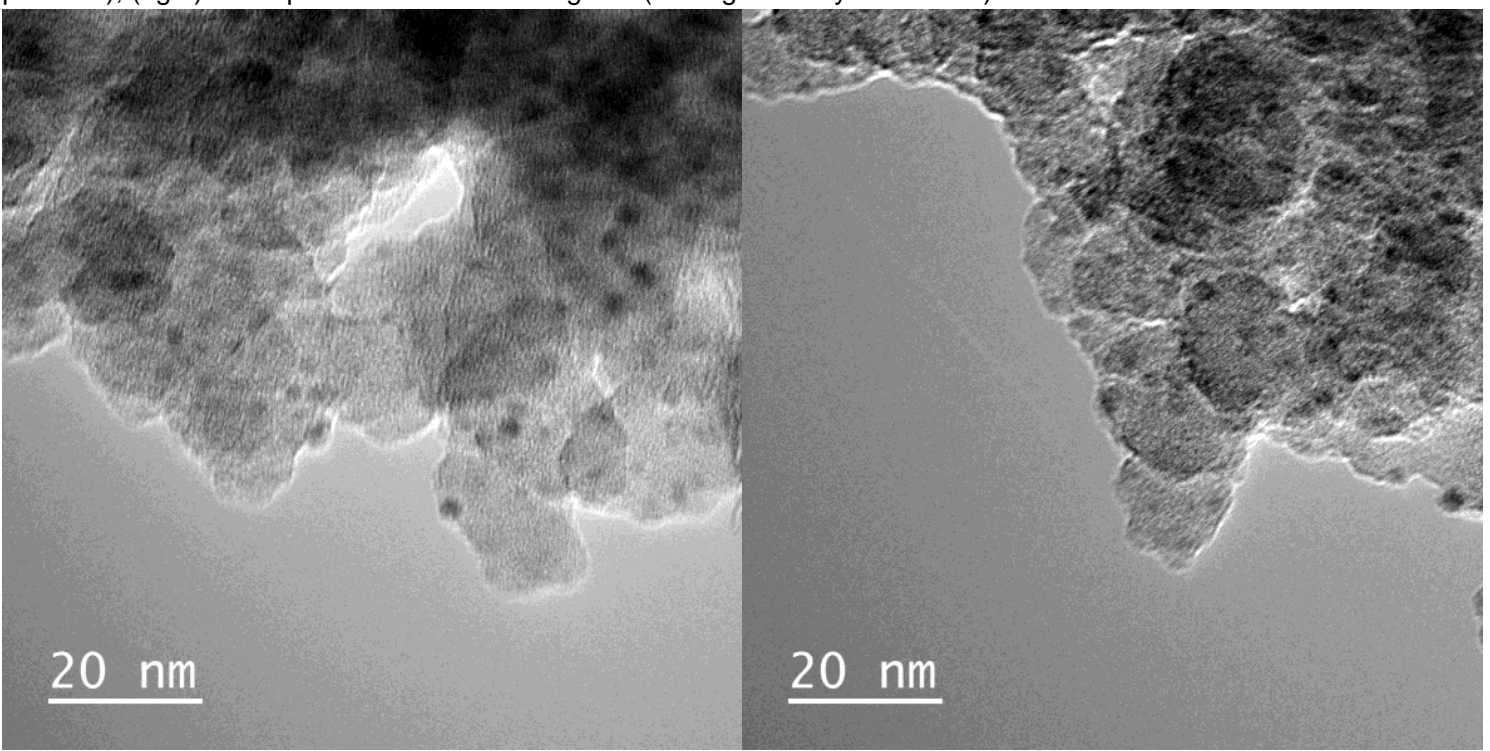

Figure S 15 - TEM images of RuWO $/ \mathrm{SiO}_{2}$ (black dots are Ru particles). 


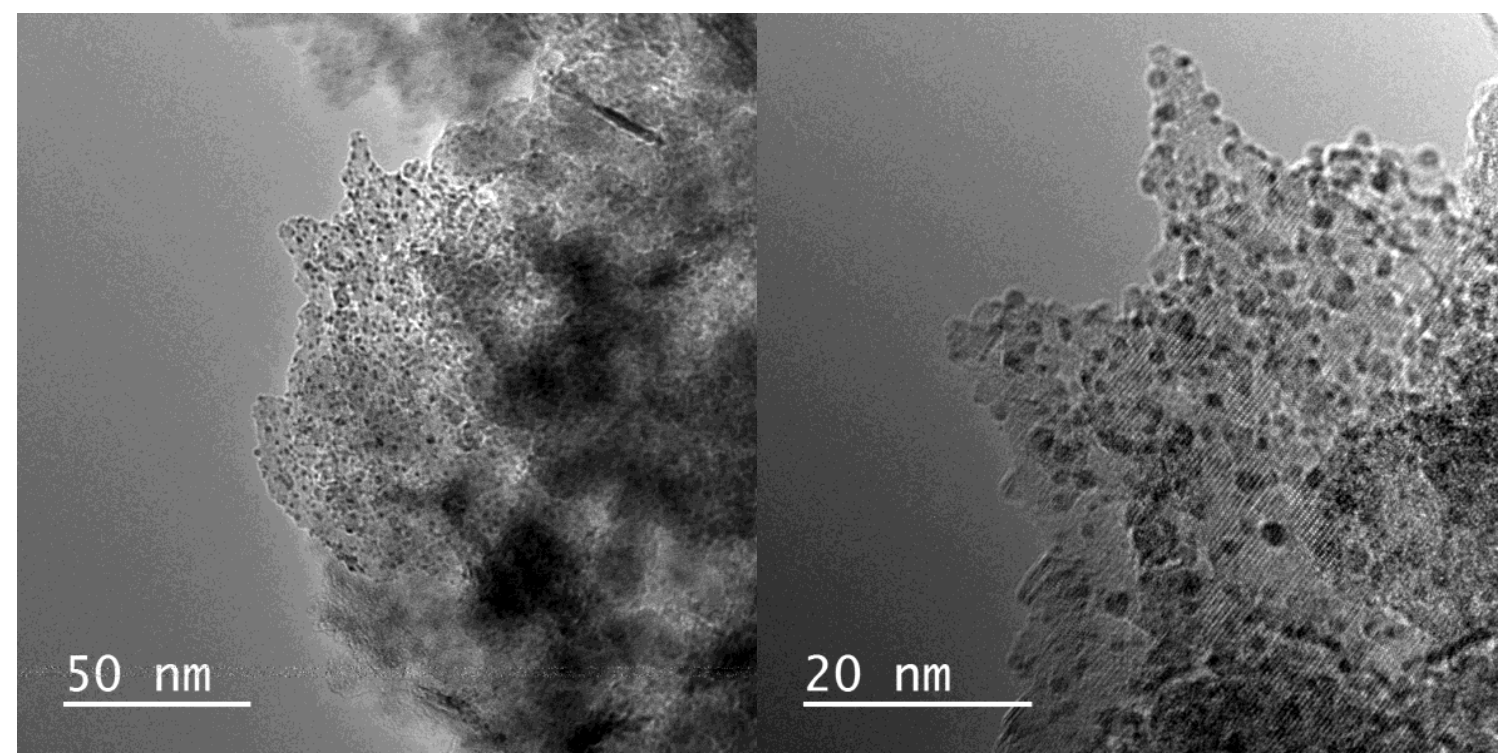

Figure S 16 - TEM images of $\mathrm{RuWO} / \mathrm{MgAl}_{2} \mathrm{O}_{4}$ catalyst (black dots are Ru particles).

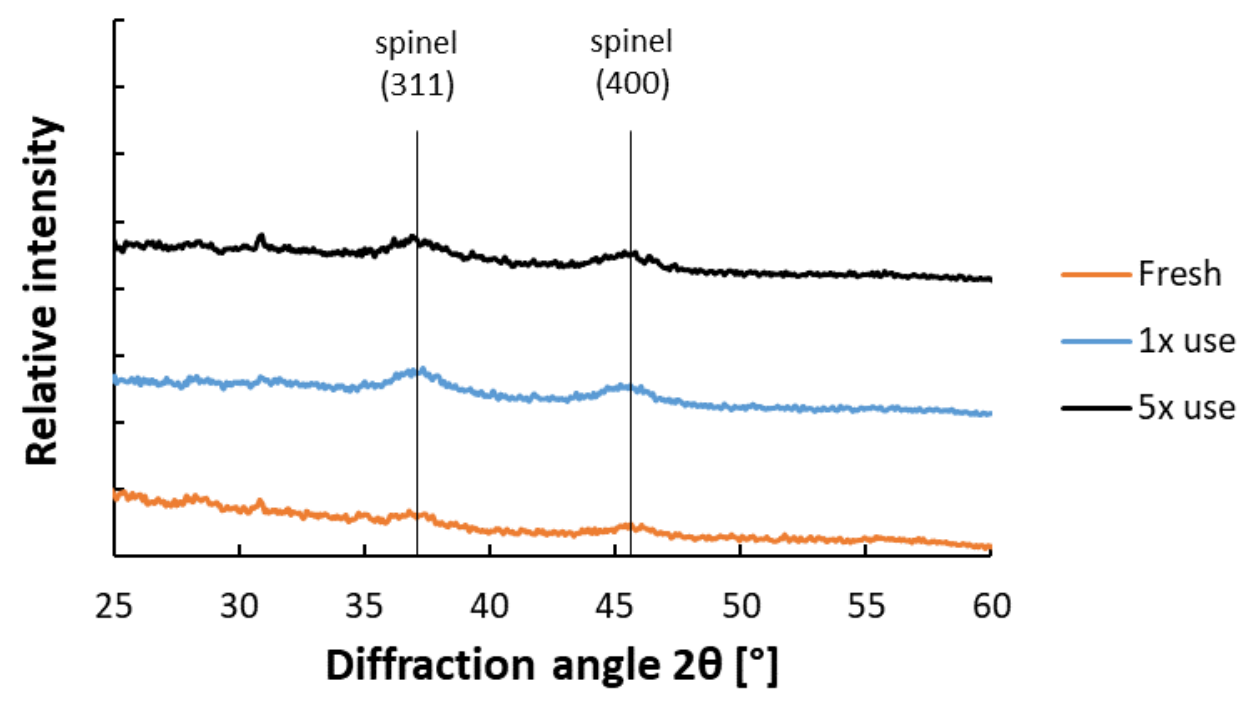

Figure $\mathbf{S} 17$ - XRD pattern of RuWO $/ \mathrm{MgAl}_{2} \mathrm{O}_{4}$ catalyst after 0,1 and 5 times used. The catalyst remains essentially the same. No peak for Ru detected since the Ru nanoparticles are too small. 


\section{Characterization of the $\mathrm{MgAl}_{2} \mathrm{O}_{4}$ spinel}

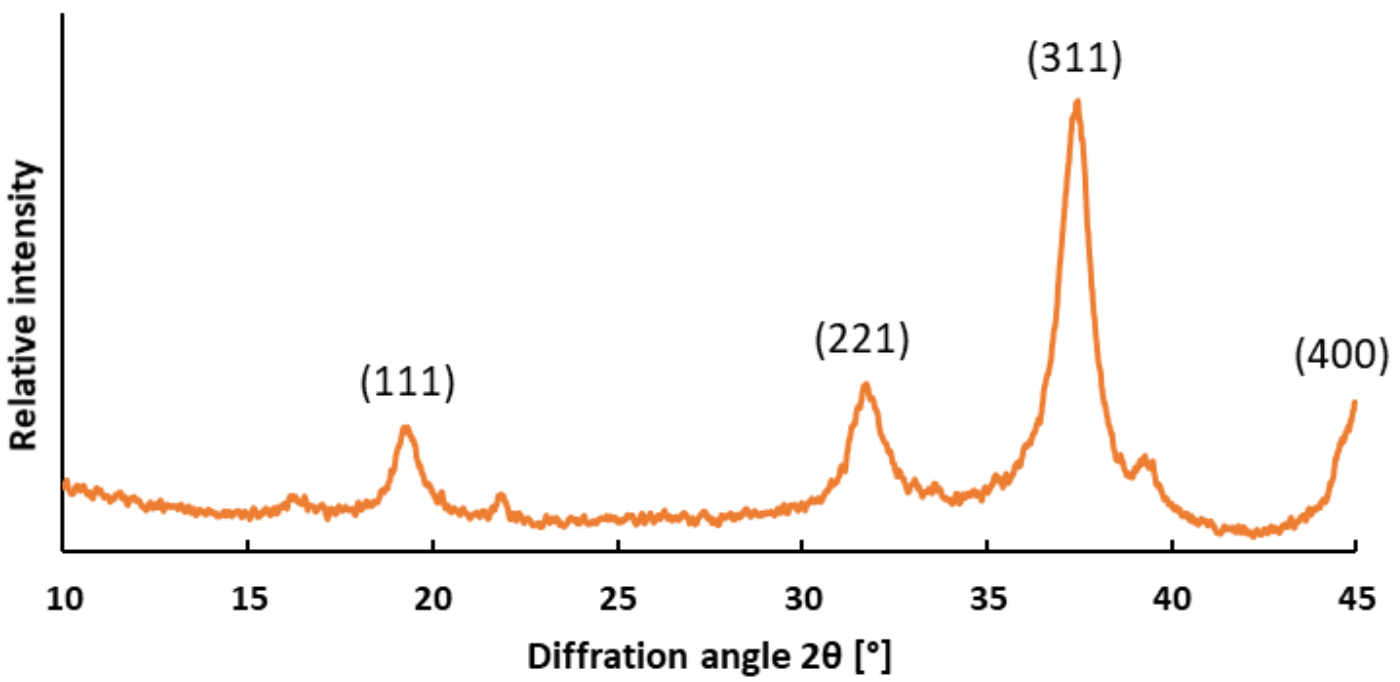

Figure S $18-X R D$ pattern of synthesized $\mathrm{MgAl}_{2} \mathrm{O}_{4}$ spinel. Diffraction planes are marked on figure.

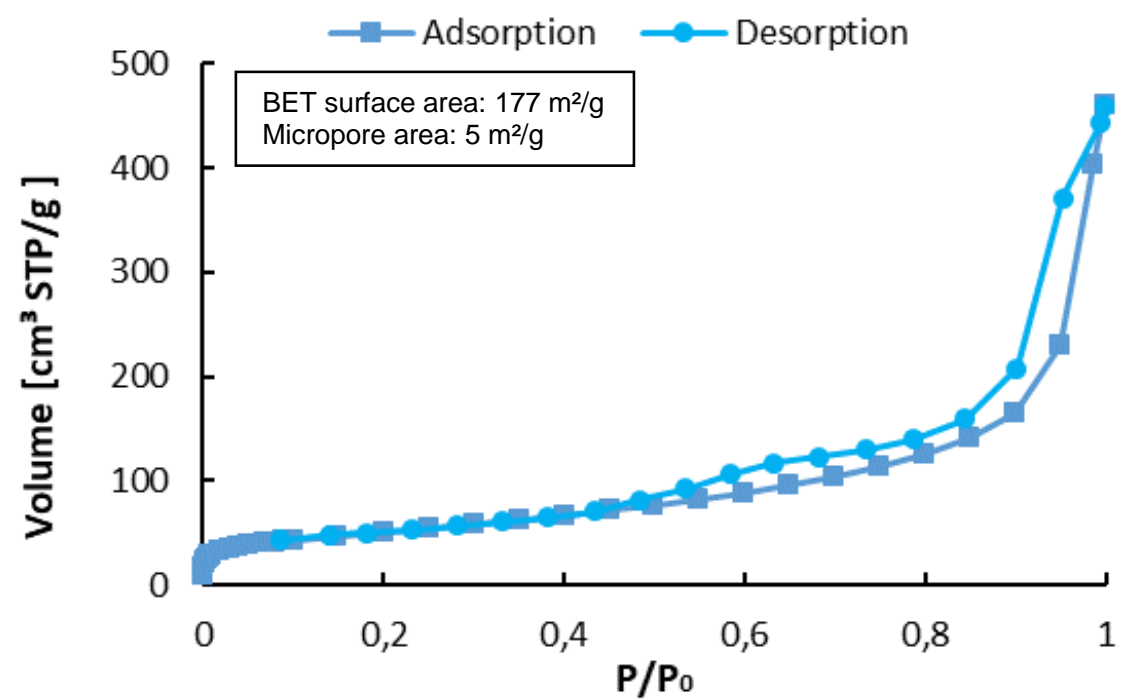

Figure $\mathbf{S} 19$ - BET surface area determination from $\mathrm{N}_{2}$-physisorption isotherm for $\mathrm{MgAl}_{2} \mathrm{O}_{4}$. 


\section{Substrate scope investigation}

\begin{tabular}{|c|c|}
\hline Substrate & Products distribution (yield) \\
\hline Hexanamide & Hexylamine (83\%), dihexylamine (17\%) \\
\hline Malonamide & Ethylamine $(23 \%)^{a}$, propylamine $(30 \%)$ \\
\hline$\varepsilon$-Caprolactam & $\begin{array}{l}\text { Hexamethylenediamine (4\%), azepane (85\%), hexylamine }(6 \%) \text {, } \\
6 \text {-(azepan-1-yl)hexan-1-amine (5\%) }\end{array}$ \\
\hline Cyclohexanecarboxamide & $\begin{array}{l}\text { Cyclohexylmethanamine (80\%), bis(cyclohexylmethyl)amine (18\%), } \\
1 \text {-cyclohexyl-N-(cyclohexylmethyl)-N-methylmethanamine (1\%), } \\
\mathrm{N} \text {-(cyclohexylmethyl)cyclopentanamine (1\%) }\end{array}$ \\
\hline Propionamide & $\begin{array}{l}\text { Propylamine }(81 \%) \text {, dipropylamine }(15 \%) \text {, propionamide }(4 \%), \\
\text { tripropylamine }(1 \%)\end{array}$ \\
\hline Octanamide & Octylamine (80\%), dioctylamine (17\%), N-octyloctanamide (3\%) \\
\hline Adipamide & $\begin{array}{l}\text { Hexamethylenediamine }(4 \%) \text {, azepane }(85 \%) \text {, hexylamine }(8 \%), \\
6 \text {-(azepan-1-yl)hexan-1-amine (3\%) }\end{array}$ \\
\hline Lauramide & $\begin{array}{l}\text { Laurylamine }(80 \%) \text {, dilaurylamine }(14 \%), N \text {-dodecyldodecaneamide } \\
(3 \%) \text {, dodecane }(1 \%)\end{array}$ \\
\hline$N$-methylpropionamide ${ }^{b}$ & Propylamine (80\%), dipropylamine (12\%), propionamide (4\%) \\
\hline $\mathrm{N}, \mathrm{N}$-dimethylpropionamide ${ }^{\mathrm{b}}$ & $\begin{array}{l}\text { Propylamine ( } 50 \%) \text {, dipropylamine }(5 \%), 37 \%) \text {, propionamide }(6 \%) \text {, } \\
N, N \text {-dimethylpropylamine }(2 \%)\end{array}$ \\
\hline$N$-acetylmorpholine ${ }^{c}$ & $\begin{array}{l}\text { Morpholine ( } 45 \%) \text {, diethylamine }(17 \%), N \text {-ethylacetamide }(7 \%) \text {, } \\
N \text {-ethylmorpholine (4\%), } N \text {-methylethanamine }(2 \%)\end{array}$ \\
\hline$N$-Hexylhexanamide & Hexylamine $(6 \%)$ \\
\hline
\end{tabular}

\section{Ammonolysis of secondary amines}

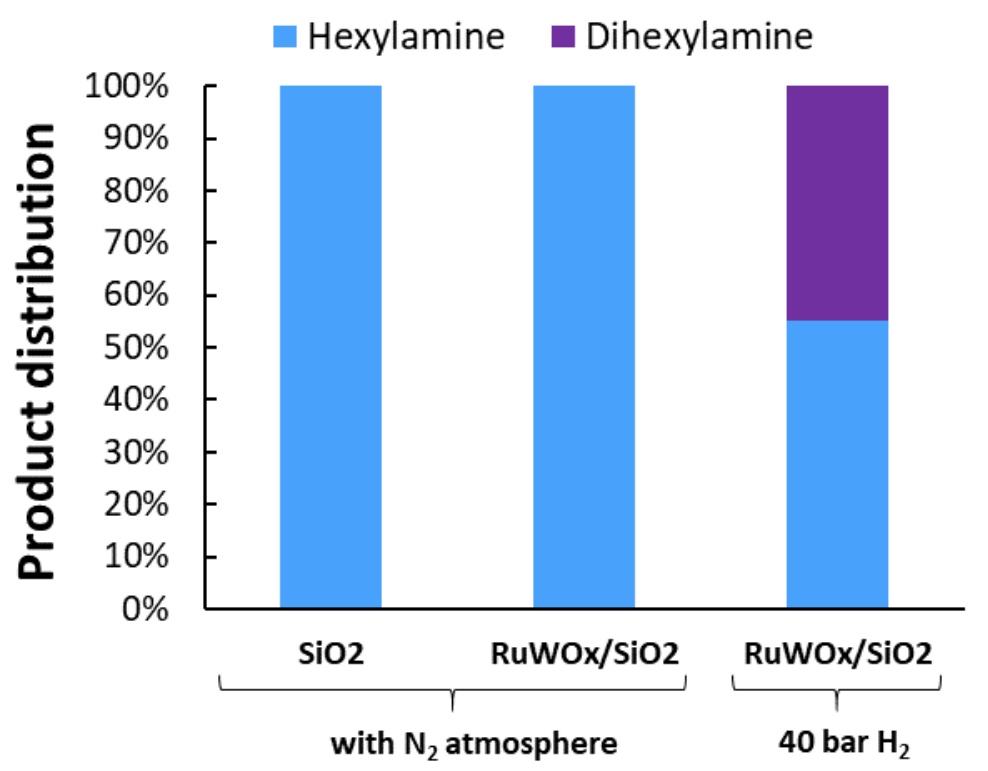

Figure S 20 - Ammonolysis of dihexylamine. Reaction conditions: hexylamine $(1 \mathrm{mmol}), 180^{\circ} \mathrm{C}, 1 \mathrm{~mol} \% \mathrm{Ru}\left(\mathrm{RuWO}_{x} / \mathrm{SiO}_{2}\right.$ or equal weight of $\mathrm{SiO}_{2}$ support), undecane $(20 \mu \mathrm{L})$, DME $(10 \mathrm{~mL}), 16 \mathrm{~h}$. 


\section{Product identification}

General information: ${ }^{1} \mathrm{H}-\mathrm{NMR}$ spectra were calibrated by setting the singlet signal of the external standard (benzyl alcohol) to $4.59 \mathrm{ppm}^{2}$

Hexylamine $(1, \mathrm{MW}=101 \mathrm{~g} / \mathrm{mol})$

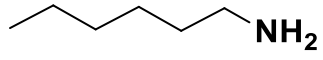

${ }^{1} \mathrm{H}-\mathrm{NMR}$ (400 MHz, methanol-d4): $\delta(\mathrm{ppm})=2.63\left(\mathrm{t}, 2 \mathrm{H}, \mathrm{NH}_{2}-\mathrm{C}_{2}-\right.$ ) 1.47 (quint, $2 \mathrm{H}, \mathrm{NH}_{2}-\mathrm{CH}_{2}-\mathrm{CH}_{2}-$ ), 1.40-1.26 (m, 6H, - $\left.\left(\mathrm{C}_{2}\right)_{3}-\mathrm{CH}_{3}\right), 0.92\left(\mathrm{t}, 3 \mathrm{H},-\mathrm{C}_{3}\right)$.

${ }^{13} \mathrm{C}-\mathrm{NMR}(400 \mathrm{MHz}, \mathrm{H} 2 \mathrm{O} / \mathrm{D} 2 \mathrm{O}): \delta(\mathrm{ppm})=41.3\left(\mathrm{NH}_{2}-\underline{\mathrm{CH}_{2}-}\right), 32.5\left(\mathrm{NH}_{2}-\mathrm{CH}_{2}-\underline{\mathrm{CH}_{2}-}\right), 31.5\left(-\left(\mathrm{CH}_{2}\right)_{2}-\underline{\mathrm{CH}}_{2}-\right)$, $26.3\left(-\underline{\mathrm{C}} \mathrm{H}_{2}-\mathrm{CH}_{2}-\mathrm{CH}_{3}\right), 22.4\left(-\underline{\mathrm{C}} \mathrm{H}_{2}-\mathrm{CH}_{3}\right), 13.6\left(-\underline{\mathrm{C}} \mathrm{H}_{3}\right)$.

GC-MS (El, 70eV): m/z (rel. int, \%): 55 (3), 45 (5), 44 (9), 43 (4), 42 (5), 41 (8), 39 (6), 30 (100), 28 (8), 27 (7).

\section{Hexanamide $(2, \mathrm{MW}=115 \mathrm{~g} / \mathrm{mol})$}<smiles>CCCCCC(N)=O</smiles>

${ }^{1} \mathrm{H}-\mathrm{NMR}\left(400 \mathrm{MHz}\right.$, methanol-d4): $\delta(\mathrm{ppm})=2.19\left(\mathrm{t}, 2 \mathrm{H},-\mathrm{C}(=\mathrm{O})-\mathrm{C}_{2} \mathbf{2}^{-}\right), 1.61$ (quint, $2 \mathrm{H},-\mathrm{C}(=\mathrm{O})-\mathrm{CH}_{2^{-}}$ $\left.\mathrm{C}_{2}-\right), 1.41-1.26\left(\mathrm{~m}, 4 \mathrm{H},-\mathrm{C}_{2}-\mathrm{C}_{2}-\mathrm{CH}_{3}\right), 0.91\left(\mathrm{t}, 3 \mathrm{H},-\mathrm{C}_{3}\right)$.

${ }^{13} \mathrm{C}-\mathrm{NMR}(400 \mathrm{MHz}, \mathrm{H} 2 \mathrm{O} / \mathrm{D} 2 \mathrm{O}): \delta(\mathrm{ppm})=178.0(-\underline{\mathrm{C}}(=\mathrm{O})-), 35.3\left(-\mathrm{C}(=\mathrm{O})-\underline{\mathrm{C}} \mathrm{H}_{2}-\right), 31.2\left(-\mathrm{CH}_{2}-\mathrm{CH}_{3}\right), 25.3$ $\left(-\mathrm{C}(=\mathrm{O})-\mathrm{CH}_{2}-\underline{\mathrm{CH}_{2}-}\right), 22.2\left(-\mathrm{CH}_{2}-\mathrm{CH}_{2}-\mathrm{CH}_{3}\right), 13.4\left(-\mathrm{CH}_{3}\right)$.

GC-MS (EI, 70 eV): m/z (rel. int., \%): 39 (19), 41 (24), 42 (14), 43 (29), 44 (52), 55 (14), 59 (100), 72 (33), $73(8), 86(23)$.

\section{Dihexylamine $(3, \mathrm{MW}=185 \mathrm{~g} / \mathrm{mol})$}

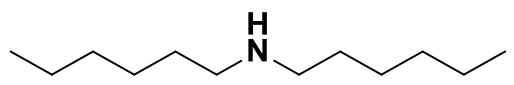

${ }^{1} \mathrm{H}-\mathrm{NMR}\left(400 \mathrm{MHz}\right.$, methanol-d4): $\delta(\mathrm{ppm})=2.57\left(\mathrm{t}, 4 \mathrm{H},-\mathrm{CH}_{2}-\mathrm{NH}-\mathrm{CH}_{2}-\right.$ ) 1.47 (quint, $4 \mathrm{H},-\mathrm{NH}-\mathrm{CH}_{2}-$ $\left.\mathrm{C}_{2}{ }^{-}\right), 1.40-1.26\left(\mathrm{~m}, 12 \mathrm{H},-\left(\mathrm{C}_{2}\right)_{3}-\mathrm{CH}_{3}\right), 0.92\left(\mathrm{t}, 6 \mathrm{H},-\mathrm{CH}_{3}\right)$.

GC-MS (El, 70eV): m/z (rel. int, \%): 185 (6), 115 (9), 114 (100), 56 (5), 55 (6), 44 (53), 43 (21), 41 (11), 30 (9), 29 (6).

\section{Trihexylamine $(4, \mathrm{MW}=269 \mathrm{~g} / \mathrm{mol})$}

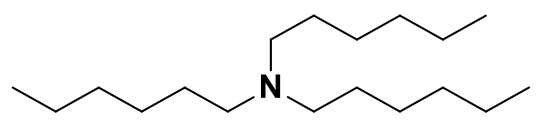

${ }^{1} \mathrm{H}-\mathrm{NMR}\left(400 \mathrm{MHz}\right.$, methanol-d4): $\delta(\mathrm{ppm})=2.43\left(\mathrm{t}, 6 \mathrm{H},-\mathrm{CH}_{2}-\mathrm{NH}-\mathrm{CH}_{2}-\right), 1.47$ (quint, $6 \mathrm{H},-\mathrm{NH}^{-} \mathrm{CH}_{2}-$ $\left.\mathrm{C}_{2}{ }^{-}\right), 1.40-1.26\left(\mathrm{~m}, 18 \mathrm{H},-\left(\mathrm{C}_{2}\right)_{3}-\mathrm{CH}_{3}\right), 0.92\left(\mathrm{t}, 9 \mathrm{H},-\mathrm{CH}_{3}\right)$.

GC-MS (El, 70eV): m/z (rel. int, \%): 200 (15), 199 (100), 128 (13), 98 (5), 58 (5), 44 (5), 43 (12), 41 (5). 
Hexanoic acid $(5, \mathrm{MW}=116 \mathrm{~g} / \mathrm{mol})$<smiles>CCCCCC(=O)O</smiles>

${ }^{1} \mathrm{H}-\mathrm{NMR}\left(400 \mathrm{MHz}\right.$, methanol-d4): $\delta(\mathrm{ppm})=2.16\left(\mathrm{t}, 2 \mathrm{H},-\mathrm{C}(=\mathrm{O})-\mathrm{C}_{2} \mathbf{2}^{-}\right), 1.61$ (quint, $2 \mathrm{H},-\mathrm{C}(=\mathrm{O})-\mathrm{CH}_{2^{-}}$ $\left.\mathrm{C}_{2}{ }^{-}\right), 1.41-1.26\left(\mathrm{~m}, 4 \mathrm{H},-\mathrm{CH}_{2}-\mathrm{C}_{2}-\mathrm{CH}_{3}\right), 0.91\left(\mathrm{t}, 3 \mathrm{H},-\mathrm{CH}_{3}\right)$.

GC-MS (El, 70eV): m/z (rel. int, \%): 87 (16), 74 (8), 73 (53), 70 (6), 61 (10), 60 (100), 57 (11), 56 (10), 55 (15), 45 (16), 43 (20), 42 (14), 41 (29), 39 (14).

Hexanol $(6, \mathrm{MW}=102 \mathrm{~g} / \mathrm{mol})$<smiles>CCCCCCO</smiles>

GC-MS (El, 70eV): m/z (rel. int, \%): 84 (5), 69 (31), 57 (9), 56 (100), 55 (52), 44 (5), 43 (54), 42 (39), 41 (42), 39 (13).

Hexane $(7, \mathrm{MW}=72 \mathrm{~g} / \mathrm{mol})$

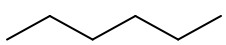

GC-MS (El, 70eV): m/z (rel. int, \%): 39 (26), 41 (77), 42 (27), 43 (51), 55 (8), 56 (52), 57 (100).

Cyclopentyl methyl ether $(8, \mathrm{MW}=100 \mathrm{~g} / \mathrm{mol})$<smiles>COC1CCCC1</smiles>

${ }^{1} \mathrm{H}-\mathrm{NMR}\left(400 \mathrm{MHz}\right.$, methanol-d4): $\delta(\mathrm{ppm})=3.81(\mathrm{~m}, 1 \mathrm{H},-\mathrm{O}-\mathrm{C} \underline{\mathrm{H}}<), 3.26\left(\mathrm{~s}, 3 \mathrm{H},-\mathrm{C}_{\underline{3}}\right), 1.79-1.48(\mathrm{~m}$, $\left.8 \mathrm{H},-\underline{\mathrm{C}}_{2}-\right)$.

GC-MS (EI, 70eV): m/z (rel. int, \%): 100 (17), 72 (11), 71 (100), 69 (8), 68 (5), 67 (9), 58 (12), 57 (11), 43 (11), 42 (7), 41 (36), 39 (20).

Cyclopentane $(9, \mathrm{MW}=70 \mathrm{~g} / \mathrm{mol})$<smiles>C1CCCC1</smiles>

GC-MS (El, 70eV): m/z (rel. int, \%): 39 (21), 41 (31), 40 (7), 42 (100), 43 (6), 55 (43), 70 (33).

1,2-Dimethoxyethane $(10, \mathrm{MW}=90 \mathrm{~g} / \mathrm{mol})$<smiles>COCCOC</smiles>

${ }^{1} \mathrm{H}-\mathrm{NMR}\left(400 \mathrm{MHz}\right.$, methanol-d4): $\delta(\mathrm{ppm})=3.49\left(\mathrm{~s}, 4 \mathrm{H},-\mathrm{O}-\mathrm{C}_{2^{-}}\right), 3.30\left(\mathrm{~s}, 6 \mathrm{H},-\mathrm{O}-\mathrm{CH}_{3}\right)$.

GC-MS (El, 70eV): m/z (rel. int, \%): 45 (100), 58 (10), 60 (16), 90 (10).

2-Methyltetrahydrofuran $(11, \mathrm{MW}=86 \mathrm{~g} / \mathrm{mol})$

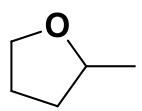

${ }^{1} \mathrm{H}-\mathrm{NMR}\left(400 \mathrm{MHz}\right.$, methanol-d4): $\delta(\mathrm{ppm})=3.98-3.82 ; 3.72-3.64\left(\mathrm{~m}, 3 \mathrm{H},-\mathrm{C}_{2}-\mathrm{O}-\mathrm{C} \underline{\mathrm{H}}-\right)$, 2.07-1.82;

1.47-1.35 (m, $\left.4 \mathrm{H},-\mathrm{CH}-\underline{\mathrm{C}}_{2}-\mathrm{CH}_{2}-\right), 1.21\left(\mathrm{~d}, 3 \mathrm{H},-\mathrm{C}_{3}\right)$. 
tert-Amyl methyl ether $(12, \mathrm{MW}=102 \mathrm{~g} / \mathrm{mol})$<smiles>CCC(C)(C)OC</smiles>

${ }^{1} \mathrm{H}-\mathrm{NMR}\left(400 \mathrm{MHz}\right.$, methanol-d4): $\delta(\mathrm{ppm})=3.17\left(\mathrm{~s}, 3 \mathrm{H},-\mathrm{O}-\mathrm{C}_{\underline{3}}\right.$ ), 1.52 (quart, $\left.2 \mathrm{H},-\mathrm{C}_{2}-\mathrm{CH}_{3}\right), 1.13$ (s, $\left.6 \mathrm{H},>\mathrm{C}<\left(\mathrm{C}_{3}\right)_{2}\right), 0.88\left(\mathrm{t}, 3 \mathrm{H},-\mathrm{CH}_{2}-\underline{\mathrm{CH}}_{3}\right)$.

tert-Amyl alcohol $(13, \mathrm{MW}=88 \mathrm{~g} / \mathrm{mol})$<smiles>CCC(C)(C)O</smiles>

${ }^{1} \mathrm{H}-\mathrm{NMR}\left(400 \mathrm{MHz}\right.$, methanol-d4): $\delta(\mathrm{ppm})=1.46$ (quart, $\left.2 \mathrm{H},-\mathrm{CH}_{2}-\mathrm{CH}_{3}\right), 1.13\left(\mathrm{~s}, 6 \mathrm{H},>\mathrm{C}<\left(\mathrm{C}_{3}\right)_{2}\right), 0.88$ $\left(\mathrm{t}, 3 \mathrm{H},-\mathrm{CH}_{2}-\mathrm{CH}_{3}\right)$.

Undecane $(14, \mathrm{MW}=156 \mathrm{~g} / \mathrm{mol})$

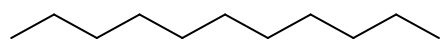

GC-MS (El, 70eV): m/z (rel. int, \%): 156 (6), 99 (5), 98 (7), 85 (32), 84 (9), 71 (51), 70 (14), 69 (6), 58 (5), 57 (100), 56 (18), 55 (16), 43 (81), 42 (12), 41 (40), 39 (9).

\section{Ethylamine $(15, \mathrm{MW}=\mathbf{4 5} \mathrm{g} / \mathrm{mol})$}

$\widehat{\mathrm{NH}_{2}}$

GC-MS (EI, 70eV): m/z (rel. int, \%): 45 (100), 44 (100), 43 (14), 42 (47), 41 (22), 40 (21), 39 (8), 38 (6).

Propylamine $(16, \mathrm{MW}=59 \mathrm{~g} / \mathrm{mol})$

$\mathrm{NH}_{2}$

GC-MS (El, 70eV): m/z (rel. int, \%): 59 (100), 58 (21), 56 (11), 54 (5), 52 (6), 44 (9), 43 (19), 42 (33), 41 (51), 40 (8), 39 (24), 38 (6).

\section{Azepane (17, MW = $99 \mathrm{~g} / \mathrm{mol})$}

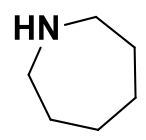

${ }^{1} \mathrm{H}-\mathrm{NMR}\left(400 \mathrm{MHz}\right.$, methanol-d4): $\delta(\mathrm{ppm})=2.87-2.71\left(\mathrm{~m}, 4 \mathrm{H},-\mathrm{C}_{\underline{2}}-\mathrm{NH}-\mathrm{C}_{2} \mathbf{2}^{-}\right), 1.74-1.49(\mathrm{~m}, 8 \mathrm{H},-\mathrm{NH}-$ $\mathrm{CH}_{2}-\mathrm{CH}_{2}-\mathrm{CH}_{2}-$.

GC-MS (El, 70eV): m/z (rel. int, \%): 99 (64), 98 (28), 84 (15), 71 (9), 70 (100), 68 (6), 57 (39), 56 (51), 55 (8), 44 (25), 43 (66), 42 (24), 41 (25), 39 (17).

Hexamethylenediamine $(18, \mathrm{MW}=116 \mathrm{~g} / \mathrm{mol})$<smiles>NCCCCCCCN</smiles>

GC-MS (El, 70eV): m/z (rel. int, \%): 108 (5), 100 (20), 99 (14), 98 (8), 87 (58), 86 (27), 82 (6), 79 (9), 77 (5), 73 (10), 72 (14), 70 (30), 69 (13), 67 (7), 59 (17), 57 (10) 56 (100), 55 (19), 54 (5), 53 (5), 45 (29), 44 (31), 43 (23), 42 (32), 41 (30), 39 (13). 


\section{Caprolactam $(19, \mathrm{MW}=113 \mathrm{~g} / \mathrm{mol})$}<smiles>O=C1CCCCCN1</smiles>

${ }^{1} \mathrm{H}-\mathrm{NMR}\left(400 \mathrm{MHz}\right.$, methanol-d4): $\delta(\mathrm{ppm})=3.22-3.15\left(\mathrm{~m}, 2 \mathrm{H},-\mathrm{NH}-\mathrm{C}_{2}-\right), 2.48-2.39(\mathrm{~m}, 2 \mathrm{H},-\mathrm{C}(=\mathrm{O})-$ $\left.\mathrm{CH}_{2}-\right), 1.82-1.48\left(\mathrm{~m}, 6 \mathrm{H},-\mathrm{NH}^{-} \mathrm{CH}_{2}-\left(\mathrm{CH}_{2}\right)_{3}-\mathrm{CH}_{2}-\mathrm{C}(=0)-\right)$.

GC-MS (El, 70eV): m/z (rel. int, \%): 114 (7), 113 (100), 86 (5), 85 (60), 84 (54), 83 (10), 69 (5), 68 (8), 67 (13), 59 (13), 57 (11), 56 (84), 55 (84), 55 (25), 54 (6), 53 (5), 44 (17), 43 (21), 42 (56), 41 (54), 40 (11), 39 (31).

Dioctylamine $(20, \mathrm{MW}=241 \mathrm{~g} / \mathrm{mol})$<smiles>CCCCCCCCNCCCCCCCC</smiles>

GC-MS (EI, 70eV): m/z (rel. int, \%): 241 (5), 143 (11), 142 (100), 57 (6), 44 (32), 43 (10), 41 (8).

\section{Octylamine $(21, \mathrm{MW}=129 \mathrm{~g} / \mathrm{mol})$}

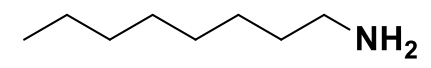

GC-MS (El, 70eV): m/z (rel. int, \%): 129 (13), 128 (8), 114 (5), 100 (26), 87 (5), 86 (52), 84 (8), 83 (12), 73 (6), 72 (17), 70 (16), 69 (33), 68 (5), 67 (6), 59 (15), 57 (9), 56 (40), 55 (48), 54 (7), 53 (10), 45 (62), 44 (75), $43(47), 42(39), 41(100), 40(8), 39(42)$.

\section{Octanamide $(22, \mathrm{MW}=143 \mathrm{~g} / \mathrm{mol})$}<smiles>CCCCCCCC(N)=O</smiles>

${ }^{1} \mathrm{H}-\mathrm{NMR}\left(400 \mathrm{MHz}\right.$, methanol-d4): $\delta(\mathrm{ppm})=2.18\left(\mathrm{t}, 2 \mathrm{H},-\mathrm{C}(=\mathrm{O})-\mathrm{CH}_{2}-\right), 1.78-1.47\left(\mathrm{~m}, 4 \mathrm{H},-\mathrm{C}(=\mathrm{O})-\mathrm{CH}_{2}-\right.$ $\left.\mathrm{C}_{2}-\mathrm{CH}_{2}-\right), 1.38-1.23\left(\mathrm{~m}, 4 \mathrm{H},-\mathrm{CH}_{2}-\underline{\mathrm{C}}_{2}-\mathrm{CH}_{3}\right), 0.90\left(\mathrm{t}, 3 \mathrm{H},-\underline{\mathrm{C}}_{3}\right)$.

GC-MS (El, 70eV): m/z (rel. int, \%): 86 (9), 73 (5), 72 (29), 59 (100), 57 (8), 55 (9), 44 (20), 43 (14), 42 (5), 41 (14), 39 (5).

\section{$N$-Hexylhexanamide $(23, \mathrm{MW}=199 \mathrm{~g} / \mathrm{mol})$}<smiles>CCCCCCNC(=O)CCCCC</smiles>

${ }^{1} \mathrm{H}-\mathrm{NMR}\left(400 \mathrm{MHz}\right.$, methanol-d4): $\delta(\mathrm{ppm})=7.29(\mathrm{~s}, 1 \mathrm{H},-\mathrm{NH}-), 3.15\left(\mathrm{t}, 2 \mathrm{H},-\mathrm{NH}-\mathrm{CH}_{2}-\right), 2.16(\mathrm{t}, 2 \mathrm{H}$, $\left.-\mathrm{C}(=\mathrm{O})-\mathrm{CH}_{2}-\right), 1.60$ (quint, $2 \mathrm{H},-\mathrm{C}(=\mathrm{O})-\mathrm{CH}_{2}-\mathrm{CH}_{2}-$ ), 1.49 (quint, $2 \mathrm{H},-\mathrm{NH}^{-} \mathrm{CH}_{2}-\mathrm{CH}_{2}-$ ) , 1.38-1.25 (m, 10H, $\left.\left.\mathrm{CH}_{3}-\left(\mathrm{C}_{2}\right)_{2}-\mathrm{R}-\mathrm{C}(=\mathrm{O})-\mathrm{NH}-\mathrm{R}^{\prime}-\left(\mathrm{C}_{2}\right)_{2}\right)_{3}-\mathrm{CH}_{3}\right), 0.91\left(\mathrm{t}, 6 \mathrm{H},-\mathrm{C}_{3}\right)$.

GC-MS (El, 70eV): m/z (rel. int, \%): 199 (8), 170 (31), 157 (10), 156 (86), 144 (7), 143 (71), 142 (6), 129 (18), 128 (52), 116 (16), 115 (5), 114 (35), 101 (29), 100 (43), 99 (62), 87 (37), 86 (54), 85 (12), 73 (53), 72 (24), 71 (35), 69 (5), 60 (9), 59 (5), 58 (15), 57 (10), 56 (10), 55 (27), 44 (40), 43 (100), 42 (13), 41 (42), 39 (11). 
$N$-Octyloctanamide $(24, \mathrm{MW}=255 \mathrm{~g} / \mathrm{mol})$<smiles>CCCCCCCNC(=O)CCCCCCC</smiles>

GC-MS (El, 70eV): m/z (rel. int, \%): 255 (16), 226 (20), 212 (20), 198 (25), 185 (13), 184 (100), 172 (7), 171 (55), 170 (6), 157 (16), 156 (49), 144 (13), 142 (17), 130 (7), 129 (8), 128 (29), 127 (39), 115 (10), 114 (44), 101 (19), 100 (38), 98 (5), 87 (30), 86 (47), 84 (8), 83 (5) 73 (63), 72 (21), 71 (17), 70 (5), 69 (12), 67 (5), 60 (9), 59 (5), 58 (15), 57 (87), 56 (11), 55 (37), 44 (41), 43 (60), 42 (12), 41 (51), 39 (8).

Cyclohexylmethanamine $(25, \mathrm{MW}=113 \mathrm{~g} / \mathrm{mol})$<smiles>NCC1CCCCC1</smiles>

GC-MS (El, 70eV): m/z (rel. int, \%): 114 (12), 113 (100), 96 (43), 95 (11), 83 (5), 82 (16), 81 (38), 79 (9), 77 (8), 70 (6), 68 (18), 67 (73), 66 (5), 65 (7), 56 (23), 55 (70), 54 (43), 53 (21), 52 (5), 51 (8), 43 (10), 42 (19), 41 (77), 39 (53).

Cyclohexanecarboxamide $(26, \mathrm{MW}=127 \mathrm{~g} / \mathrm{mol})$<smiles>NC(=O)C1CCCCC1</smiles>

GC-MS (El, 70eV): m/z (rel. int, \%): 127 (39), 126 (13), 112 (15), 99 (9), 98 (40), 86 (18), 85 (10), 84 (5), 83 (38), 82 (6), 81 (7), 79 (5), 73 (10), 72 (96), 69 (5), 67 (14), 59 (64), 56 (16), 55 (100), 54 (11), 53 (11), 44 (31), 43 (7), 42 (7), 41 (50), 39 (25).

\section{Cyclohexylmethanol $(27, \mathrm{MW}=114 \mathrm{~g} / \mathrm{mol})$}<smiles>OCC1CCCCC1</smiles>

GC-MS (El, 70eV): m/z (rel. int, \%): 96 (22), 84 (5), 83 (68), 82 (28), 81 (57), 68 (15), 67 (45), 66 (5), 56 (6), 55 (100), 54 (13), 53 (9), 43 (7), 42 (7), 41 (45), 39 (21).

Bis(cyclohexylmethyl)amine $(28, \mathrm{MW}=209 \mathrm{~g} / \mathrm{mol})$<smiles>C1CCC(CNCC2CCCCC2)CC1</smiles>

GC-MS (El, 70eV): m/z (rel. int, \%): 209 (5), 127 (9), 126 (100), 97 (6), 55 (23), 44 (33), 43 (7), 41 (11). $N$-(cyclohexylmethyl)cyclohexanecarboxamide $(29, \mathrm{MW}=223 \mathrm{~g} / \mathrm{mol})$<smiles>O=C(NCC1CCCCC1)C1CCCCC1</smiles>

GC-MS (EI, 70eV): m/z (rel. int, \%): 223 (10), 168 (17), 141 (20), 140 (8), 129 (8), $128(100), 112$ (10), 111 (17), 97 (6), 86 (9), 83 (43), 81 (7) 73 (8), 67 (9), 55 (42), 44 (11), 41 (19), 39 (5). 
Dodecanamide $(30, \mathrm{MW}=199 \mathrm{~g} / \mathrm{mol})$<smiles>CCCCCCCCCCCC(N)=O</smiles>

GC-MS (El, 70eV): m/z (rel. int, \%): 128 (5), 114 (5), 86 (8), 73 (6), 72 (40), 60 (6), 59 (100), 57 (7), 55 (11), 44 (15), 43 (17), 41 (15).

\section{Dodecylamine (31, MW = $185 \mathrm{~g} / \mathrm{mol})$}

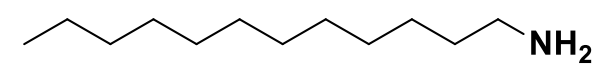

GC-MS (EI, 70eV): m/z (rel. int, \%): 185 (12), 184 (9), 170 (5), 156 (14), 142 (15), 128 (12), 114 (15) 111 (6), 100 (34), 98 (6), 97 (13), 87 (7), 86 (59), 84 (10), 83 (18), 82 (6), 73 (9), 72 (21), 71 (5), 70 (16), 69 (36), 68 (6), 67 (8), 59 (20), 57 (23), 56 (41), 55 (67), 54 (7), 53 (8), 45 (59), 44 (78), 43 (71), 42 (27), $41(100), 39(21)$

Didodecylamine $(32, \mathrm{MW}=354 \mathrm{~g} / \mathrm{mol})$<smiles>CCCCCCCCCCCCNCCCCCCCCCCCC</smiles>

GC-MS (EI, 70eV): m/z (rel. int, \%): 199 (15), 198 (100), 196 (5), 57 (8), 56 (5), 55 (7), 44 (19), 43 (9), $41(7), 30$ (5).

$N$-Dodecyldodecanamide $(33, \mathrm{MW}=368 \mathrm{~g} / \mathrm{mol})$<smiles>CCCCCCCCCCCNC(=O)CCCCCCCCCCC</smiles>

GC-MS (El, 70eV): m/z (rel. int, \%): 368 (5), 367 (18), 338 (10), 324 (15), 310 (9), 296 (20), 282 (19), 268 (12), 254 (22), 241 (17), 240 (100), 228 (12), 227 (61), 213 (14), 212 (55), 207 (5), 200 (9), 198 (11), 186 (14), 184 (20), 183 (15), 170 (13), 156 (12), 142 (16), 129 (5), 128 (18), 115 (9), 114 (36), 101 (16), 100 (27), 98 (8), 97 (7), 87 (23), 86 (34), 85 (13), 84 (8), 83 (11), 81 (5), 73 (47), 72 (16), 71 (21), 70 (6), 69 (19), 60 (8), 58 (9), 57 (55), 55 (39), 44 (27), 43 (71), 42 (8), 41 (37).

\section{Morpholine (34, MW = $87 \mathrm{~g} / \mathrm{mol})$}<smiles>C1COCCN1</smiles>

GC-MS (EI, 70eV): m/z (rel. int, \%): \%): 87 (77), 86 (37), 58 (7), 57 (100), 56 (49), 43 (6), 42 (17), 41 (6).

$N$-Ethylmorpholine $(35, \mathrm{MW}=115 \mathrm{~g} / \mathrm{mol})$<smiles>CCN1CCOCC1</smiles>

GC-MS (El, 70eV): m/z (rel. int, \%): 115 (37), 101 (6), 100 (100), 84 (5), 70 (12), 58 (7), 57 (85), 56 (25), $54(6), 43(6), 42(88), 41(8)$. 
Diethylamine $(36, \mathrm{MW}=73 \mathrm{~g} / \mathrm{mol})$

$\widehat{\mathbf{N}} \widehat{\mathrm{H}}$

GC-MS (EI, 70eV): m/z (rel. int, \%): 39 (8), 41 (14), 42 (43), 44 (24), 55 (14), 56 (5), 58 (100), 70 (12), $72(14), 73(25)$.

$N$-Ethylacetamide $(37, \mathrm{MW}=87 \mathrm{~g} / \mathrm{mol})$<smiles>CCNC(C)=O</smiles>

GC-MS (EI, 70eV): m/z (rel. int, \%): 87 (100), 72 (21), 44 (65), 43 (85), 42 (20), 41 (6).

$N$-Methylethanamide $(38, \mathrm{MW}=59 \mathrm{~g} / \mathrm{mol})$<smiles>CCNC</smiles>

GC-MS (El, 70eV): m/z (rel. int, \%): 59 (42), 58 (27), 56 (7), 44 (100), 43 (8), 42 (14), 41 (4), 30 (23), 29 (8), 27 (9).

\section{$\mathrm{N}, \mathrm{N}$-Dimethylpropanamine $(39, \mathrm{MW}=87 \mathrm{~g} / \mathrm{mol})$}<smiles>CCCN(C)C</smiles>

GC-MS (El, 70eV): m/z (rel. int, \%): 87 (13), 58 (100), 44 (9), 42 (12).

$\mathrm{N}, \mathrm{N}$-Dimethylpropanamide $(40, \mathrm{MW}=101 \mathrm{~g} / \mathrm{mol})$<smiles>CCC(=O)N(C)C</smiles>

${ }^{1} \mathrm{H}-\mathrm{NMR}\left(400 \mathrm{MHz}\right.$, methanol-d4): $\delta(\mathrm{ppm})=3.07\left(\mathrm{~s}, 3 \mathrm{H},-\mathrm{N}-\mathrm{C}_{3}{ }_{3}\right), 2.94\left(\mathrm{~s}, 3 \mathrm{H},-\mathrm{N}-\mathrm{C}_{3}\right), 2.40$ (quart, $2 \mathrm{H}$, $\left.-\mathrm{C}(=\mathrm{O})-\mathrm{C}_{2}-\right), 1.11\left(\mathrm{t}, 3 \mathrm{H},-\mathrm{CH}_{2}-\mathrm{C}_{3}\right)$.

GC-MS (El, 70eV): m/z (rel. int, \%): 101 (100), 73 (5), 72 (79), 58 (11), 57 (36), 56 (6), 55 (5), 46 (7), 45 (44), 44 (78), 43 (6), 42 (23).

N-Methylpropanamide $(41, \mathrm{MW}=87 \mathrm{~g} / \mathrm{mol})$<smiles>CCC(=O)NC</smiles>

${ }^{1} \mathrm{H}-\mathrm{NMR}\left(400 \mathrm{MHz}\right.$, methanol-d4): $\delta(\mathrm{ppm})=2.68\left(\mathrm{~s}, 3 \mathrm{H},-\mathrm{NH}-\mathrm{CH}_{3}\right.$ ), 2.17 (quart, $2 \mathrm{H},-\mathrm{C}(=\mathrm{O})-\mathrm{C}_{2}-$ ), 1.07 $\left(\mathrm{t}, 3 \mathrm{H},-\mathrm{CH}_{2}-\mathrm{CH}_{3}\right)$.

GC-MS (El, 70eV): m/z (rel. int, \%): 87 (75), 86 (6), 59 (5), 58 (100), 57 (33), 56 (33), 55 (6), 44 (15). 
Propionamide $(42, \mathrm{MW}=73 \mathrm{~g} / \mathrm{mol})$<smiles>CCC(N)=O</smiles>

${ }^{1} \mathrm{H}-\mathrm{NMR}\left(400 \mathrm{MHz}\right.$, methanol-d4): $\delta(\mathrm{ppm})=2.21$ (quart, $2 \mathrm{H},-\mathrm{C}(=\mathrm{O})-\mathrm{C}_{2^{-}}$), 1.12 (t, 3H, $-\mathrm{C}_{3}$ ).

GC-MS (EI, 70eV): m/z (rel. int, \%): 99 (7), 73 (60), 72 (14), 70 (34), 57 (21), 56 (5), 55 (7), 44 (100), 42 (6).

\section{Ethanol $(43, \mathrm{MW}=46 \mathrm{~g} / \mathrm{mol})$}

$\widehat{O H}$

GC-MS (El, 70eV): m/z (rel. int, \%): 42 (11), 43 (20), 44 (10), 45 (100), 46 (35).

Dipropylamine $(44, \mathrm{MW}=101 \mathrm{~g} / \mathrm{mol})$<smiles>CCCNCCC</smiles>

GC-MS (EI, 70eV): m/z (rel. int, \%): 39 (5), 41 (15), 42 (5), 43 (20), 44 (11), 58 (6), 72 (100), 73 (5), 101 (15).

6-(azepan-1-yl)hexan-1-amine (45, MW = $198 \mathrm{~g} / \mathrm{mol})$<smiles>NCCCCCCN1CCCCCC1</smiles>

GC-MS (El, 70eV): m/z (rel. int, \%): 41 (6), 42 (5), 55 (6), 58 (8), 112 (100), 113 (8).

1,10-Diaminodecane $(46, \mathrm{MW}=172 \mathrm{~g} / \mathrm{mol})$<smiles>NCCCCCCCCCCN</smiles>

GC-MS (El, 70eV): m/z (rel. int, \%): 39 (12), 41 (40), 42 (17), 43 (23), 44 (75), 45 (38), 53 (5), 54 (6), 55 (44), $56(60), 57(8), 59(27), 67(10), 68(6), 69(32), 70(20), 72(26), 73(11), 81$ (7), $82(6), 83(12), 86$ (45), 87 (11), 95 (5), 97 (9), 98 (6), 100 (45), 101 (5), 114 (31), 128 (36), 129 (5), 142 (21), 143 (72), 144 (8), 156 (100), 157 (12).

$N^{1}$-(10-aminodecyl)decane-1,10-diamine $(47, \mathrm{MW}=327 \mathrm{~g} / \mathrm{mol})$<smiles>NCCCCCCCCCCNCCCCCCCCCCN</smiles>

GC-MS (El, 70eV): m/z (rel. int, \%): 44 (11), 55 (7), 56 (6), 156 (6), 171 (6), 185 (100), 186 (13).

Adipamide $(48, \mathrm{MW}=144 \mathrm{~g} / \mathrm{mol})$<smiles>NC(=O)CCCCC(N)=O</smiles>

${ }^{1} \mathrm{H}-\mathrm{NMR}\left(400 \mathrm{MHz}\right.$, methanol-d4): $\delta(\mathrm{ppm})=2.32\left(\mathrm{t}, 2 \mathrm{H},-\mathrm{C}(=\mathrm{O})-\mathrm{C}_{2^{-}}\right), 1.76-1.70(\mathrm{~m}, 4 \mathrm{H}$, $-\mathrm{C}(=\mathrm{O})-\mathrm{CH}_{2}-\mathrm{C}_{2}-{ }^{-}$. 
Lauramide $(49, \mathrm{MW}=144 \mathrm{~g} / \mathrm{mol})$<smiles>CCCCCCCCCCCC(N)=O</smiles>

${ }^{1} \mathrm{H}-\mathrm{NMR}\left(400 \mathrm{MHz}\right.$, methanol-d4): $\delta(\mathrm{ppm})=2.19\left(\mathrm{t}, 2 \mathrm{H},-\mathrm{C}(=\mathrm{O})-\mathrm{C}_{2}-\right)$ ) 1.60 (quint, $2 \mathrm{H}$, $\left.-\mathrm{C}(=\mathrm{O})-\mathrm{CH}_{2}-\mathrm{C}_{2}-\right), 1.38-1.22\left(\mathrm{~m}, 8 \mathrm{H},-\left(\mathrm{C}_{2}\right)_{8}-\mathrm{CH}_{3}\right), 0.90\left(\mathrm{t}, 3 \mathrm{H},-\underline{\mathrm{C}}_{3}\right)$.

$N$-Acetylmorpholine $(50, \mathrm{MW}=129 \mathrm{~g} / \mathrm{mol})$<smiles>CC(=O)N1CCOCC1</smiles>

GC-MS (El, 70eV): m/z (rel. int, \%): 41 (6), 42 (22), 43 (75), 44 (6), 54 (5), 55 (6), 56 (63), 57 (100), 58 (9), 70 (5), 71 (5), 72 (10), 86 (59), 87 (16), 99 (5), 114 (36), 129 (53).

\section{References supporting information}

(1) Guo, J., Lou, H., Zhao, H., Wang, X., \& Zheng, X. Materials Letters, 2004, 58, 1920-1923.

(2) Babij, N. R., et al. Organic Process Research and Development, 2016, 20, 661-667. 